\title{
Factors that Affect Students' Performance In Science: An Application Using Gini-BMA Methodology On PISA 2015 Dataset
}

\author{
ANASTASIA DIMISKI \\ University of Guelph*
}

\begin{abstract}
Existing theoretical and empirical evidence on the determinants of students' performance reveals a direct link between pre-primary education and achievement test scores in primary school. Relying on the first-of-its-kind 2015 wave data from the Programme of International Student Assessment (PISA), the present study analyses the associations between students' performance in science and a broad set of variables, including regressors that proxy pre-primary education. Employing a Gini Regression Bayesian Model Averaging (BMA) approach to account for model uncertainty, it is found that non-attendance in pre-primary education is a robust determinant with a negative impact on students' performance in science. This result is confirmed both under Gini-BMA and OLS-BMA methodology.
\end{abstract}

Keywords: students' performance, pre-primary education, Gini regression coefficient, BMA methodology, PISA.

JEL classification: C11;C38;I21;J24

\section{Introduction}

Formal education is without any doubt one of the major concerns for policy makers since it determines an individual's income and amplifies inequalities of economic and social opportunities. A study by Carniero and Heckman (2003) points out that investments in human capital have dynamic complementarities and that skills obtained in the child's lifetime expedite the development of additional future skills. So, "learning begets learning" and generates important benefits in terms of medium and long-term schooling and socio-economic outcomes, including the promotion of productivity and economic efficiency. Among all educational stages, there is an emerging consensus that early childhood education interventions provide a cognitively simulating environment that enhance school readiness, academic performance, social integration, and longterm skill development (Myers (1995), Entwisle and Alexander (1993), Waldfogel (2002), Brooks-

\footnotetext{
* PhD student at University of Guelph, Canada, email: adimiski@uoguelph.ca. I thank Prof. Stengos Thanasis for helpful comments and suggestions. I gratefully acknowledge the comments and advice of the anonymous referee that have improved the presentation of the paper. The usual disclaimer applies.

(C) 2021 Anastasia Dimiski. Licensed under the Creative Commons Attribution - Noncommercial 4.0 Licence (http: //creativecommons.org/licenses/by-nc/4.0/. Available 
Gunn (2003), Carniero and Heckman (2003)). Becker (1964) is of the view that early childhood investments bring higher returns compared to future investments because recipients have a longer time to enjoy the benefits. Along the same lines, a study by Heckman (2006) reveals that preprimary education generates the highest possible annual return that gradually fades at higher levels of education program.

This study investigates the associations between students' performance in science and a set of variables that are classified into 14 categories, including attendance and non-attendance in preprimary education. These indicators are relative to students', families' and schools' characteristics. To test this, a large cross-national dataset, the 2015 round of the Programme for International Student Assessment (PISA) is applied. Due to the limited number of observations, Principal Component Analysis is applied to reduce the dimensionality of the dataset, while retaining as much as possible of the variation present in it. Therefore, motivated by the proliferation of possible explanatory variables in explaining students' performance in science and the relative absence of guidance from economic theory, 43 variables are taken simultaneously into consideration. To ensure a comprehensive search, Gini-BMA methodology and OLS-BMA methodology are employed.

Bayesian Model Averaging (BMA) approach constructs estimates that do not depend on a particular model specification, but rather they are conditional on the model space. Thus, inference is averaged over models, forming a weighted average of model specific estimates where the weights are given by the posterior model probabilities. This framework permits to consider a wider range of possible explanatory variables and to end up with those that can effectively explain the relationship. To estimate the coefficients, Gini regression methodology is incorporated into the BMA. The Gini methodology is a rank-based methodology that takes into consideration both the variate values and their ranks and it is based on the Gini Mean Difference (GMD) as a measure of dispersion. Among the two types of Gini regression coefficients that can be attributed to GMD, the focus has been on the semi-parametric approach. The semi-parametric nature of the Gini regression coefficient is justified because it does not rely on the linearity assumption nor on any distributional assumptions and the regression coefficients can simply be interpreted as weighted average of slopes. Even though both the OLS and Gini share an underlining linear structure, they differ in that the estimated marginal responses (i.e., the BMA unconditional posterior means (PSE) as presented in Table 5) are generated differently and in the case of the Gini in a much more robust fashion. This fits well in using a BMA approach that relies on the uncertainty that surrounds the estimates of beta coefficients (i.e., the BMA unconditional posterior means (PSE) as presented in Table 5). Using alternative semi-parametric methods based on local smoothers (Pagan and Ullan (1999)) would not lend themselves directly to the use of BMA since the estimation of marginal effects would not be expressed in a single coefficient as in the case of both OLS and Gini. 


\section{DIMISKI Student Performance in Science}

A comparison between the Gini-MA results and the OLS-MA ones suggests that the determinants that are important under Gini analysis are not necessarily similar to the ones that are important under OLS analysis. Among the most important outcomes found in this study is the effect of pre-primary schooling on students' test scores. In particular, the results grounded in both Gini and OLS coefficients suggest that the "percentage of students who had not attend pre-primary education" has a negative impact on science test scores. Also, the regressor "attendance in preprimary education" was found to be strongly robust with a surprisingly negative effect on students' performance and only under the Gini-MA analysis. As was argued, that apparent negative result may conceal the significant variation in years of pre-primary education and the potential benefits and costs between too many or too few years of pre-primary education. In other words, the apparent negative result of the "attendance in pre-primary education" variable reflects the significant trade -offs that may exist between entering pre-primary education at a very early age and missing out on parental care at these very early ages, while it is clear that some pre-primary education is crucial and important, but not at all costs. (Entwisle and Alexander (1993), Myers (1995), Waldfogel (2002), Brooks-Gunn (2003), Carniero and Heckman (2003), Velez et.al (1993), Wößmann (2005), Bjorklund and Salvanes (2011), Waldfogel and Washbrook (2011, and press b)).

Children tend to reap the greatest benefits if preschool programs are of high quality (Carneiro and Heckman (2003). Most of the economic research on this topic recognizes that pre-primary education of exclusive quality is a high-yield investment with longstanding benefits (Gormley et. al. (2005), Heckman and Lochner (2000), Reynolds et. al. (2011)). Also, along with the early childhood interventions, many studies have found that home conditions are another crucial determinant of child's educational achievement (Bjorklund and Salvanes,2011). Both Velez et.al (1993) and Wößmann (2005) agree that, apart from preschool attendance, parental involvement and family features are key components in students' performance. Becker $(1981,1985)$ and Becker and Tomes (1986) embrace the theory of family to provide a reasonable justification for the failure of preschool education.

Apart from pre-primary education, there are also other factors that stand out for their influence on students' performance. In a recent study, Helal et. al. (2019) identify three classes of factors that lead to lower academic performance: the socio-demographic factor, which involves all students from indigent socio-economic background and those with special entry requirements, the academic one which includes all students with limited access to the course resources and forum and the course assessment factor, which refers to students with low level contributions to the course level activities or to students who study-off campus or part-time. According to Tinajero et. al (2012), Brazilian university students' academic achievement is significantly enhanced by cognitive style and learning strategies. Hanushek and Wößmann (2006) take into consideration institutional 
differences by splitting schools into differing and non-differing ability systems and examine their impact on students' mean performance.

The contribution of this paper to the current literature is threefold. First, it is a contribution to the narrow literature that focuses on the factors that affect students' performance in science. For this purpose, 43 variables, classified into 14 categories, are taken simultaneously into consideration. Most importantly, it attempts to shed a light on the following question: Does preprimary education comprise a crucial factor for students' performance in science? Second, this is among the very first studies that exploit OECD's PISA 2015 dataset. Third, it is the first time that Gini regression methodology is incorporated into the BMA one, to calculate the variables' coefficients.

The remainder of this paper is structured as follows. The second section is the literature review for the pre-primary education. The third section presents the literature review for BMA methodology. The fourth section describes the BMA methodology with particular emphasis on prior model and parameter structures. The fifth section describes the theory for Gini regression coefficient. The sixth section describes the PISA data. The seventh section discusses the empirical results. The final section concludes.

\section{Literature Review for pre-primary education}

A growing literature is increasingly acknowledging the importance of early childhood interventions as an indispensable tool in nations building, as it has been argued that early interventions determine educational and labour market outcomes later in life (Cunha, Heckman, Lochner and Masterov,2006). As early childhood is considered a susceptible period for brain development and language acquisition (Heckman, Krueger and Friedman (2002); Knudsen, Heckman, Cameron and Shonkoff (2006)), pre-primary education assures a smooth transition to primary education and establishes the basis for later learning. A study by Carniero and Heckman (2003) points out that investments in human capital have dynamic complementarities and that skills obtained early in the child's lifetime expedite the development of additional future skills. So, early learning makes subsequent learning easier and generates important benefits in terms of medium and long-term schooling and socio-economic outcomes.

Early exposure to pre-primary schooling engenders supportive environment for the new intakes to easily adjust to formal school and develop essential social skills that lead to peer acceptance and academic achievement. (Myers 1992; Knight and Hughes 1995). Evidence abounds in the literature of the direct link between pre-school experience and academic performance. Entwisle and Alexander (1993) relate later school achievements to the children's academic skills obtained at school entry, while Berlinski et. al. (2009) links pre-primary school education to short-term gains in test scores and behavioral outcomes (e.g. attention, class participation, effort, and discipline). 


\section{DIMISKI Student Performance in Science}

However, as is indicated by Behrman and Birdsall (1983), focusing exclusively on the quantity of pre-schooling might lead to misleading results because the variation in quality is substantial too. Using five different structural quality indicators, Bauchmüller et. al. (2014) find persistent, although modest, positive relationships between high quality early childhood care and children's test outcomes at the end of the primary school's $9^{\text {th }}$ grade. In contrast, Chetty et.al. (2011) argues that high quality has a positive impact in cognitive development but is not lasting, since it fades out after few years. Goodman and Sianasi (2005) find that early education is related to improvements in cognitive skills at age 7, but the impact is short-lived since it remains important throughout the schooling years up to age 16. Similarly, using data from the Early Childhood Longitudinal Study, Manguson et. al. (2007) show that pre-school enrolment in the United States is associated with higher reading and mathematics skills at the time of entry into the first grade, but these effects dissipate for most children by the end of the first grade.

There are several reasons that justify the diminishing trend of/in gains from early childhood interventions. Esping-Andersen et. al. (2012) and Reynolds (1993,2000) state that children at risk due to family's low-income, poverty and other related factors cannot secure a continuous development if there is no a coherent, continual and adequate support provided by government funded preschool and primary grade intervention programs. Specifically, Zigler and Berman (1983) mention that a one-year intervention cannot "inoculate a child against continuing disadvantage" (p.898). Barnett (2011) mentions that interventions are not compelling when graduates from the early educational intervention programs attend public schools with limited efficiency. Further, Schulman et. al. (1999) and Barnett et.al (2004) acknowledge that although most of the states, across the United States, have established prekindergarten curriculum standards, they differ in terms of quality, accessibility, and availability of resources. Most importantly, few of them have established mechanisms to implement these comprehensive standards/prekindergarten initiatives.

Along with the early childhood interventions, many studies have found that home conditions are another crucial determinant of child's educational achievement (Bjorklund and Salvanes,2011). Both Velez et.al (1993) and Wößmann (2005) agree that, apart from preschool attendance, parental involvement and family features are key components in students' performance. A child's development begins within the family and depends on the parents' educational and cultural levels (Wößmann, 2005). Waldfogel and Washbrook (2011, and press b) support that parents that are educated and receive high income, spend more time to prepare their children's reading skills. In contrast, parents with lower income and less education have more possibilities to engage in harsh and incompatible parenting teaching behaviours that may negatively affect child's progress. Becker (1981, 1985) and Becker and Tomes (1986) embrace the theory of family to provide a reasonable justification for the failure of preschool education. Many authors correlate family's income with 
the quality of pre-school education too (Bainbridge et al., 2005; Magnuson and Waldfogel, 2005; Meyers et al.,2004). Low-income families are less likely to enrol their children to pre-school care, and if they do, they are most likely to be characterized by low-quality. In contrast, children from prosperous families are more likely to be registered in high-quality pre-schools. Attending systematically poorer quality pre-schools is an additional reason why gains from pre-school may eventually fade (Esping-Andersen et. al.,2012).

Expanding pre-primary education is an effective instrument to improve school progression and raise average achievement for less advantaged children. Extensive research has been conducted both on the short-run and long-run effects (see among others Barnett (1992), Barnett (1995), Danziger and Waldfogel (2000), Currie (2001), Blau and Currie (2006), Ludwig and Miller (2007)). Dumas and Lefranc (2010) find that extending pre-school enrolment in France is beneficial in terms of schooling outcomes, including test scores, for children from disadvantaged households. Heckman et. al. (2013) evaluate the results of the early childhood education Perry Preschool program that targeted to children from economically disadvantaged families. Outcomes reveal that children who participated in this program tended to create improvements in personality skills and enhance academic motivation. In particular, there is a boost in the long-term achievement test scores, with the effect being stronger for girls than for boys. Research suggests that disadvantaged children take the greatest advantage if, these special programs are of high quality (Gormley et al. (2005), Heckman and Lochner (2000), Neuman, Kamerman, Waldfogel, and Brooks-Gunn (2003), Reynolds et al. (2011), Waldfogel (2006)). Although there is ample empirical evidence that early childhood intervention programs have significant positive effects on the results of children from disadvantaged or minority background, it is not clear whether such pre-school programs influence the outcomes of children in the population as a whole. As typical preschool or prekindergarten programs vary in the quality of learning environments they provide and in the availability of financial resources, little is known about whether universal intervention can promote children's cognitive and academic outcomes (Gilliam and Zigler (2001)).

Many recent papers document the effects of universal preschool enrolment on the education of children in the entire population in a variety of other counties. Estimates obtained for developing counties testify positive and in some cases long-lasting effects of preschool attendance. Exploiting the information given by the Uruguayan Household Survey, Berlinski et. al. (2008) notice that attendance in pre-primary education reduces the probability for grade retention, grade failure and early drop-out during the primary and secondary schooling years. Aguilar and Tansini (2012) recognize that early exposure to pre-primary education has a positive effect on children's performance in the first year at public schools in Montevideo, Uruguay, and this effect remains positive but weakens after six years. Berlinski et.al. (2009) study the effects of Argentina's expansion of universal pre-primary schooling and find that pre-primary education positively affects 


\section{DIMISKI Student Performance in Science}

third grade standardized Spanish and Mathematics test scores as well as students' behavioral skills. Taiwo and Tyolo (2002) notice that first grade Botswana students with pre-school experience achieve higher scores in English language, mathematics and science compared to students without such an experience. Using data for Thailand obtained from the Programme of International Student Assessment (PISA) for the years 2009 and 2012, Pholphirul (2017) reveals that pre-schooling attributes positively on cognitive skills in reading, mathematics and science with the mother's education attainment being a decisive factor on child's enrollment to preschool. According to this information, early exposure to pre-primary schooling appears as a successful and cost-effective policy to prevent late entry, early drop-out rates and early grade failure in poor countries, where large share of young population is excluded from compulsory education already at an early age (UNESCO, 2005).

There is considerable evidence for the impact of universal early childhood schooling in developed countries too. Using Census data, Cascio (2009) examines the long-run results of an expansion in universal kindergarten in the late 60 s and early 70 s across the United States. She reports no effect on the labour market outcomes and regarding the educational ones, the only positive influence is the reduction in grade retention. Goux and Maurin (2008) apply a differencein-difference approach and find that one additional year in pre-elementary school in French has no important effect on children's subsequent educational skills. Baker et. al. (2005) show that the establishment of full-time and highly- subsidized kindergartens in the Canadian province of Quebec in the late 1990s, corresponds to an increase in the labour supply by married women and a decline in children's outcomes. Similarly, Dickson (2012) displays that the extension of free early education in the UK to all three -year- olds does not have any impact on reading, writing and mathematics when children reach the age seven. Only for deprived Local Education Authorities the results turn to be positive. In contrast Gormley and Gayer (2005) find that Oklahoma's universal pre-school program contributes positively to cognitive scores. In Japan, the expansion of both kindergartens and nursery schools is associated with higher achievement rates both in high school and college (Akabayashi and Tanaka (2013)).

\section{Literature Review for Bayesian Model Averaging (BMA) approach}

Classical Statistical Analysis disregards the theory and specification uncertainty, which jointly refer to as model uncertainty. As indicated by Leamer (1983), whimsical decisions about choice of functional forms and control variables leads to fragile inferences based on economic data. Bayesian Model Averaging (BMA) has successfully addressed model uncertainty in the model selection process, providing a comprehensible mechanism to embody ambiguity into conclusions about parameters. To construct estimates, it does not condition on a specific set of theories and covariates, but rather extracts information from a universe of candidate models. The result is a weighted average of model specific estimates, where posterior model probabilities are employed as weights. 
The initial approach to deal with model averaging dates back to Roberts $(1965)^{1}$, who proposed a marginal distribution for outcomes of any unobserved sample, the so-called "predictive distribution". This distribution is defined as the weighted averaged of posterior probabilities of two models. Building up to this idea, Leamer $(1978,1983)$ presented Extreme Bound analysis and set the fundamentals for the BMA methodology ${ }^{2}$. This technique was further studied by Raftery (1988, 1993), George and McCulloch (1993), Madigan and Raftery (1994), Drapper (1995), Kass and Raftery (1995), Kass and Wasserman (1995), Raftery, Madigan and Hoeting (1997), Hoeting et all (1999) among others.

BMA has proven a valuable tool in empirical settings with alternative theories, transmission mechanisms, a massive number of covariates and a limited number of observations. Empirical growth theory is a characteristic example. Theory uncertainty appears extensively in growth regressions since different theories, which use a specific subset of regressors, cannot exclude other compatible and interrelated theories from also being suitable. Brock and Durlauf (2001) refer to this by theory open-endedness, implying that existing growth theories needs to be considered when the effect of a specific growth theory on growth is to be analyzed. Apart from the aforementioned, Fernandez, Ley and Steel (2001a), Doppelhofer, Miller and Sala-i-Martin (2004), Durlauf, Kourtellos and Tan (2008), Durlauf, Kourtellos and Tan (2012), Massanjala and Papageorgiou (2008), Eicher, Papageorgiou and Raftery (2011), Ley and Steel (2007) are among those who endorse the use of this methodology to generate robust growth determinants.

Economic forecasting is another field which is affected by model uncertainty, since forecasts often depend on the model selected. Insightful contributions of forecast uncertainty can be found in Garratt, Lee, Pesaran and Shin (2003), Min and Zellner (1993), Raftery, Madigan and Hoeting (1997), Fernandez, Ley and Steel (2001 a, b), Ley and Steel (2009). In the context of forecasting inflation, Koop and Korobolis (2012) apply dynamic model averaging and selection strategies in state-space models to allow for both the coefficients in each model and the forecasting model to evolve over time. An alternative approach to predict inflation is used in Eklund and Karlsson (2007) who replace the standard marginal likelihood with the so-called forecast weights.

The rapid utilization of BMA in a variety of economic applications include examples from policy evaluation (Brock, Durlauf and West (2003), Sirimaneetham and Temple (2006), Kourtellos, Stengos and Tan (2013)), inequality (Kourtellos and Tsangarides (2017)), monetary policy (Levin and Williams (2003)), environmental economics (Begun and Eicher (2008)), returns to education (Tobias and Li (2004)) and intergenerational mobility (Kourtellos, Marr and Tan (2015)).

\footnotetext{
${ }^{1}$ Regarding model selection, an initial approach is given by Efroymson (1960) who introduced the stepwise regression analysis.

${ }^{2}$ Levine and Renelt (1992) apply Extreme Bound Analysis to cross-country data and conclude that very few or none of the regressors robustly affect growth. To overcome possible difficulties arising from the implementation of this methodology, alternative solutions have been suggested (Leamer (1985), Granger and Uhlig (1990), Sala-i-Martin (1997)).
} 


\section{DIMISKI Student Performance in Science}

\section{Bayesian Model Averaging (BMA) methodology}

BMA provides a probabilistic framework to simultaneously deal with model and parameter uncertainty. To describe the relationships between all the unknown parameters and the data, a joint probability distribution is needed. To construct estimates, instead of conditioning on a single model, a model space $\mathrm{M}=\left\{\mathrm{M}_{1}, \ldots, \mathrm{M}_{\mathrm{k}}\right\}$ is taken into consideration, whose elements cover all the possible regressors suggested by the literature. For multiple model setups, it proceeds by assigning prior probability distributions to each model and to the parameters of each model. Combining those priors with the distribution for the data and conditioning on the data, results in the posterior distribution of model uncertainty, which allows for model selection and inferences ${ }^{3}$.

Considering the case of normal linear regression models, model uncertainty occurs from the selection of the "best" model, or alternatively, from the selection of the explanatory variables to include in the right-hand side:

$$
Y=\beta_{0}+\sum_{j=1}^{q}\left(\beta_{j} X_{j}+\varepsilon\right)=X B+\varepsilon, \varepsilon \sim \mathrm{N}\left(0, \sigma^{2} \mathrm{I}_{\mathrm{n}}\right)
$$

where $\mathrm{Y}$ and $\varepsilon$ are $\mathrm{nx} 1$ vectors of the dependent variable and the error term respectively, $\mathrm{X}$ is a $\mathrm{nxq}$ matrix of candidate regressors that may or may not be included in the model, B is an nxq matrix with the parameters to be estimated and $n$ is the total number of observations. If some of the elements of the parameter vector, $\beta=\left(\beta_{1}, \beta_{2}, \ldots . \beta_{\mathrm{q}}\right)$ equal zero, there are $2^{\mathrm{q}}$ candidate models in total to be estimated, indexed by $M_{k}$ for $k=1, \ldots ., 2^{q}$. Each of these models offers to explain the data and represents a distinct subset of the candidate regressors. For instance, model $\mathrm{M}_{\mathrm{k}}$ takes the form:

$$
Y=\sum_{j=1}^{q_{k}} \beta_{j}^{(k)} X_{j}^{(k)}+\varepsilon
$$

where $\mathrm{Y}$ is the dependent variable, $\varepsilon$ is the normal error term, $X_{1}^{(k)}, \ldots, X_{q_{k}}^{(k)}$ is a subset of $\mathrm{X}_{1}, . . \mathrm{X}_{\mathrm{q}}$ and $\beta=\left(\beta_{1}{ }^{(k)}, \ldots ., \beta_{q k}{ }^{(k)}\right)$ is a vector of regression coefficients to be estimated. The vector $\theta_{k}=\left(\beta_{0}\right.$, $\left.\beta^{(\mathrm{k})}, \sigma\right)$ summarizes the parameters for the given model $\mathrm{M}_{\mathrm{k}}$.

The implementation of a pure Bayesian approach addresses model uncertainty, but its implementation rests firmly on solving the common challenge of specifying the priors over models in the model space and the prior distribution for the parameters of each model. Elicitation of prior parameters can be extremely critical for the outcome and any differences in the results can be attributed to the use of alternative prior assumptions. It is acknowledged (Fernandez, Ley and Steel (2001b), Kass and Raftery (1995), George (1999a) that posterior model probabilities, which are

3 For an excellent and detailed explanation of Bayesian model averaging see Raftery, Madigan, Hoeting (1997), Hoeting, Madigan, Raftery and Volinsky (1999), Sala-i-Martin (1997), Clyde and George (2004), Chipman, George, McCulloch (2001) and Steel (2020). 
employed as weights for averaging estimates across models, are sensitive to the specification of priors over model-specific parameters. More detailed discussion about model and parameter priors can be found in Steel (2020) as well as in the Appendix.

Motivated by the proliferation of possible explanatory variables in explaining students' performance in science and the relative absence of guidance from economic theory, 43 variables are taken simultaneously into consideration. These quality indicators are relative to students', families' and schools' characteristics and are classified into 14 categories: Educational outcomes, Participation in Education, Fields of education, Student evaluation and assessment, Classroom environment/school climate, Students' engagement drive and beliefs, After-school activities, Access to ICT, Performance and socio-economic status, Performance and diversity, Resources for education, Professional development of teachers, School evaluation and Governance. More detailed description is provided in Table 4. BMA approach is employed by calculating the weighted average of model specific estimates using Gini and OLS estimates. The weights attached to each estimate is identical to posterior model probabilities. Being totally agnostic about whether any of these regressors is included in the true model, a prior probability of 0.5 is attached to each one, implying a uniform model prior. Regarding the parameter space, the unit information prior (UIP) is adopted, where the integrated likelihood is proxied by the Schwarz Information Criterion (SIC). According to Eicher, Papageorgiou and Raftery (2011), the combination of the unit information prior with a uniform prior over the model space generally outperforms competing priors. Considering an extremely large set of possible models, by allowing for any subset of up to 43 regressors to be included into the model, the Bayesian framework undertakes the specification uncertainty in a straightforward and formal way. It deals with a set of $2^{43}=8.8 \times 10^{12}$ (over eight trillion) different models. To determine this numerical problem and, following Madigan and York (1995) and Lee and Steel (2007), Markov Chain Monte Carlo (MCMC) techniques are practiced, using the so-called Markov chain Monte Carlo Model Composition $\left(M C^{3}\right)$ sampler, with $5 \times 10^{6}$ recorded draws after a burn-in of 1 million draws.

\section{Gini Regression Coefficient}

Although Least Squares methodology ranks as one of the most popular practices for estimating the relationship between a set of regressors on the conditional expected value of the dependent variable, it relies on certain assumptions, whose violations might result in non-robust estimates. The Gini regression, introduced by Olkin and Yitzhaki (1992), is proposed as an alternative. Its utilization is justified whenever the investigator wants to relax the traditional assumptions, such as the convenient world of normality and the linearity of the model. The Gini methodology is a rankbased methodology that takes into consideration both the variate values and their ranks and it is based on the Gini Mean Difference (GMD) as a measure of dispersion ${ }^{4}$.

\footnotetext{
${ }^{4}$ The GMD as a measure of spread/variability was first initiated by Corrado Gini (1912).
} 
Between the at least 14 distinct presentations that exist for GMD, the focus has been on the formula that relies on covariances (Lerman and Yitzhaki (1984)) ${ }^{5}$. That is, if $F(X)$ is the cumulative distribution function which is uniformly distributed on $[0,1]$, the GMD is expressed as:

$$
G=4 E\{X(F(X)-E[F(X)])\}=4 \operatorname{cov}[X, F(X)]
$$

which is four times the covariance between a random variable $\mathrm{X}$ and its cumulative distribution function $\mathrm{F}(\mathrm{X})$. Equivalently, the above can be rewritten as:

$$
G=\frac{1}{3} \frac{\operatorname{cov}[X, F(X)]}{\operatorname{cov}[F(X), F(X)]}
$$

which equals the one third of the slope of the OLS regression curve of the dependent variable, as a function of the observation's positions in the array, $\mathrm{F}(\mathrm{X})$, having arrayed the observations in ascending order. Alternatively, it is the weighted average of the slopes defined between two adjacent observations.

There are two types of Gini regressions related to GMD. The first one, known as the Rregression (Hettmansperger (1984)), is based on the minimization of the GMD of the residuals. The second one, known as the semi-parametric approach (Olkin and Yitzhaki (1992)), imitates the OLS methodology by replacing the variance-based expressions by the equivalent GMD terms ${ }^{6}$. The combination of these two allows one to identify and test whether the implicit assumptions about the underlying distributions are supported by the data or not. Apart from that, the superiority of the Gini-based analyses also lies on the fact that Gini estimators are robust to the existence of extreme values or measurement errors and to the asymmetry of the distribution. Under that case, heavy tailed distributions can be used (Serfling (2010)). In addition, only the first moment conditions are needed for the Gini methodology to be implemented (Stuart and Ord (1987, p.58)). Focusing on the second approach, and assuming a simple regression, the population semiparametric Gini regression coefficient is based on the covariance presentation of the GMD and is obtained by replacing the covariance expressions in the OLS regression coefficient by the corresponding Gini covariances:

$$
\beta^{N}=\frac{\operatorname{cov}[Y, F(X)]}{\operatorname{cov}[X, F(X)]}
$$

\footnotetext{
${ }^{5}$ For a complete overview of the Gini methodology, the reader is referred to Yitzhaki and Schechtman (2013).

${ }^{6}$ The Gini estimator taken by the second approach cannot be characterized as "the best" because it is not derived by solving a minimization problem. In contrast, the one derived by the first approach is optimal but it does not have an explicit presentation and it is only expressed numerically.
} 
where $\mathrm{F}(\mathrm{X})=\mathrm{R}(\mathrm{X})$ represents the regressor's rank ${ }^{7}$.

For the case of multiple Gini regression coefficients, a set of linear equations composed of simple Gini regression coefficients must be solved. Starting from the multiple regression model, expressed in population parameters:

$$
Y=a+\beta_{1} X_{1}+. .+\beta_{K} X_{K}+\varepsilon
$$

and defining $\mathrm{K}$ random variables $\mathrm{R}\left(\mathrm{X}_{1}\right), \mathrm{R}\left(\mathrm{X}_{2}\right), . ., \mathrm{R}\left(\mathrm{X}_{\mathrm{K}}\right)$, the following identities hold:

$$
\begin{gathered}
\operatorname{cov}\left(Y, R\left(X_{1}\right)\right)=\beta_{1} \operatorname{cov}\left(X_{1}, R\left(X_{1}\right)\right)+. .+\beta_{K} \operatorname{cov}\left(X_{K}, R\left(X_{1}\right)\right)+\operatorname{cov}\left(\varepsilon, R\left(X_{1}\right)\right) \\
\operatorname{cov}\left(Y, R\left(X_{2}\right)\right)=\beta_{1} \operatorname{cov}\left(X_{1}, R\left(X_{2}\right)\right)+. .+\beta_{K} \operatorname{cov}\left(X_{K}, R\left(X_{2}\right)\right)+\operatorname{cov}\left(\varepsilon, R\left(X_{2}\right)\right) \\
\vdots \\
\operatorname{cov}\left(Y, R\left(X_{K}\right)\right)=\beta_{1} \operatorname{cov}\left(X_{1}, R\left(X_{K}\right)\right)+. .+\beta_{K} \operatorname{cov}\left(X_{K}, R\left(X_{K}\right)\right)+\operatorname{cov}\left(\varepsilon, R\left(X_{K}\right)\right)
\end{gathered}
$$

Setting

$$
\beta_{\varepsilon j}=\frac{\operatorname{cov}\left(\varepsilon, R\left(X_{j}\right)\right)}{\operatorname{cov}\left(X_{j}, R\left(X_{j}\right)\right)}, \beta_{k j}=\frac{\operatorname{cov}\left(X_{k}, R\left(X_{j}\right)\right)}{\operatorname{cov}\left(X_{j}, R\left(X_{j}\right)\right)}, \beta_{0 j}=\frac{\operatorname{cov}\left(Y, R\left(X_{j}\right)\right)}{\operatorname{cov}\left(X_{j}, R\left(X_{j}\right)\right)}
$$

with $\mathrm{k}, \mathrm{j}=1,2, \ldots, \mathrm{K}$ and dividing the three last equations by, respectively, $\operatorname{cov}\left(\mathrm{X}_{1}, \mathrm{R}\left(\mathrm{X}_{1}\right)\right)$, $\operatorname{cov}\left(X_{2}, R\left(X_{2}\right)\right)$, and $\operatorname{cov}\left(X_{k}, R\left(X_{k}\right)\right)$, under the assumption that $\operatorname{cov}\left(X_{k}, R\left(X_{k}\right)\right) \neq 0,(k=1,2, . ., K)$, yields:

$$
\begin{gathered}
\beta_{01}=\beta_{1} 1+. .+\beta_{K} \beta_{K 1}+\beta_{\varepsilon 1} \\
\beta_{02}=\beta_{1} \beta_{12}+. .+\beta_{K} \beta_{K 2}+\beta_{\varepsilon 2} \\
\vdots \\
\beta_{0 K}=\beta_{1} \beta_{1 K}+. .+\beta_{K} \beta_{K K}+\beta_{\varepsilon K}
\end{gathered}
$$

where the index 0 illustrates the dependent variable, $\beta_{\varepsilon j}$ and $\beta_{k j}$ are the regression coefficients in the simple regressions of $\mathrm{X}_{\mathrm{k}}$ on $\mathrm{R}\left(\mathrm{X}_{\mathrm{k}}\right)$ and $\beta_{0 j}$ are the semi-parametric Gini regression coefficients as given in presentation (5).

Rearranging, defining the following column vectors $\beta_{0}=\left(\beta_{01}, \beta_{02}, \ldots, \beta_{0 K}\right), \beta_{\varepsilon}=\left(\beta_{\varepsilon 1}, \beta_{\varepsilon 2}, . ., \beta_{\varepsilon K}\right)$ and provided that the rank of the matrix that consists of the $\beta_{\mathrm{k}}$ 's coefficients is $\mathrm{K}$, it comes:

${ }^{7}$ Empirically the regressor's rank $\mathrm{R}_{\mathrm{x}}$ is computed by the formula $R(X)=\frac{\sum_{i=1}^{N} R\left(X_{i}\right)}{N}$. 


$$
\left[\begin{array}{c}
\beta_{1} \\
\vdots \\
\beta_{K}
\end{array}\right]=\left[\begin{array}{cccc}
1 & \beta_{21} & \ldots & \beta_{K 1} \\
\vdots & \vdots & \vdots \\
\beta_{K 1} & \cdots & & 1
\end{array}\right]^{-1}\left[\begin{array}{ccc}
\beta_{01}- & \beta_{\varepsilon 1} \\
\vdots & \\
\beta_{0 K}- & \beta_{\varepsilon K}
\end{array}\right]=A^{-1}\left[\beta_{0}-\beta_{\varepsilon}\right]
$$

where $\mathrm{A}^{-1}$ is a $\mathrm{K} \times \mathrm{K}$ matrix while the $\beta$ 's are $\mathrm{K} \times 1$ vectors.

Imposing the set of restrictions, known as "orthogonality conditions", described by:

$$
\beta_{\varepsilon k}=0, \text { for } k=1,2, \ldots, K
$$

the identities of (10) turn into:

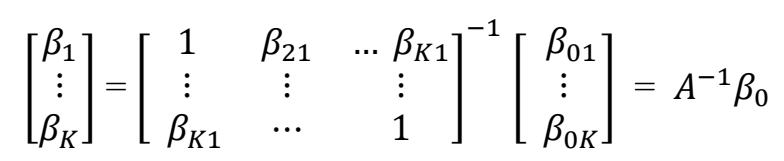

or equivalently

$$
\beta^{G I N I}=\left[\begin{array}{cccc}
1 & \beta_{21} & \cdots & \beta_{K 1} \\
\vdots & \vdots & & \vdots \\
\beta_{K 1} & \cdots & & 1
\end{array}\right]^{-1}\left[\begin{array}{c}
\beta_{01} \\
\vdots \\
\beta_{0 K}
\end{array}\right]=A^{-1} \beta_{0}
$$

The previous expression shows the Gini estimator $\beta^{G I N I}$ is a function of slope coefficients of semiparametric simple Gini regressions $\beta_{0}$. Consequently, it is a semi-parametric Gini estimator.

Since, most of the concepts and parameters in the Gini framework are parallel in structure to the OLS framework, it is natural to view presentation (5) as an OLS instrumental variable (IV), where $\mathrm{F}(\mathrm{X})=\mathrm{R}(\mathrm{X})$ serves as an instrument ${ }^{8}$. According to Olkin and Yitzhaki (1992), when the model is given by:

$$
Y=X B^{G I N I}+\varepsilon
$$

where $\mathrm{Y}$ is the dependent variable $\left(\mathrm{N} \times 1\right.$ vector), $\mathrm{X} \equiv\left[x_{i k}\right]$ is the matrix of regressors $(\mathrm{N} \times \mathrm{K}$ with the first column of ones), $B^{G I N I}$ is the vector of parameters to be estimated ( $\left.\mathrm{K} \times 1\right)$ and $\varepsilon$ is the

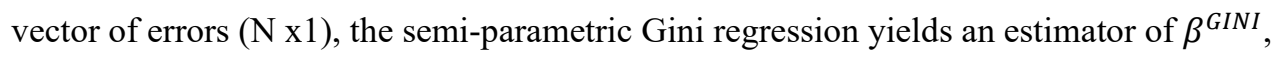

$$
\beta^{G I N I}=\left(R_{x}^{\prime} X\right)^{-1} R_{x}^{\prime} \mathrm{Y}
$$

where $\mathrm{R}_{\mathrm{x}}=\mathrm{R}(\mathrm{X})$.

\footnotetext{
${ }^{8}$ Although the Gini regression framework can imitate the OLS concepts, they differ in interpretations and properties. Under the Gini IV analysis, the concept of IV is applied twice. As a first step, the sample's empirical cumulative distribution function replaces the variable, without questioning the validity of the rank to serve as an IV. As a next step, another variable that satisfies all the conditions from an IV perspective is required (Yitzhaki and Schechtman (2004)).
} 
Review of Economic Analysis 13 (2021) 157-211

\section{Data}

\subsection{Analyzing PISA DATA}

PISA (or alternatively, Programme of International Student Assessment) is created by the Organization for Economic Co-operation and Development (OECD) to test the 15-year-old students' skills and knowledge in reading, mathematics and science. Through this procedure vital information is collected regarding students' ability to compete globally, to collaborate for problem solving, to think critically and creatively. What students know and can do, where all students can succeed and what school life means for students' lives are the three questions that constitute the core of this triennial international education survey. Seventy-nine countries and economies and a sample of 600,000 students among 32 million in total, participate in a two-hour test carried out every three years 9 . Only students between the age of 15 years and 3 months and 16 years and 2 months can engage in this survey, while the choice of schools and students is as broad as possible so that a wider range of different educational backgrounds and abilities to be covered.

The PISA test's content is based on the curricula found across the world, without promoting or imposing anyone of those and neither there is a need to find similar characteristics between them. The goal is to assess countries' performance by providing scores for each subject area while the mean score in each subject can be used to rank the participating economies. Since the test is not designed to evaluate individual students, a considerable number of alternative test forms, covering all aspects of test material, exists and gives the opportunity to obtain a much greater coverage of the content $t^{10}$. The results, in each test subject, are scaled to follow normal distributions, with mean around 500 score points and standard deviations around 100 score points for OECD countries. Due to the fact that only a sample of students from each country is tested, the estimates are accompanied with statistical uncertainty, meaning that it is impossible to assign an exact rank to each participating country, based on its mean score, but rather to place it within a range of positions (that is, between an upper and a lower rank).

To allow comparisons among countries and to conclude whether performance for each country is improved or not, PISA scores are reported at the same scale over time. Under these circumstances, both year-to-year comparisons are feasible and average trends over three or more assessment years can be calculated. Having this information, PISA identifies effective policies and practices that are implemented in economies that record high performance, or in economies that show significant improvement over time. It further, reinforces the participating members that are

9 PISA Programme was first launched in 2000. Every three years the main subject of assessment in PISA changes, moving from reading, to mathematics and finally to science and starting all over again, while for the other two subjects PISA provides a summary assessment.

${ }^{10}$ PISA has a two-stage stratified sampling design. Within each participating country a random sample of schools is selected, and then a random sample of students is selected within each school (OECD, 2009). More detailed information on the recruitment, sampling design, procedures and assessment methods are available in a series of technical reports at https://www.oecd.org/pisa/data/2015-technical-report/ 


\section{DIMISKI Student Performance in Science}

willing to engage in similar programs, acknowledging that there is no one education model that fits all members, since different economies share different characteristics.

PISA is established and enforced under the authority of education ministries through the PISA Governing Board, the PISA's decision-making body. All member countries plus partner countries with Associate status elect representatives to the Board, who are a mix of government officials and staff of research and academic institutions. The Board regulates the PISA's policy priorities and standards for data development, analysis and reporting, and supervises their implementation. PISA's financial support is exclusively derived from direct contributions from the participating economies' education ministries ${ }^{11}$.

The PISA database has been widely applied in many different studies since it provides the huge advantage to allow for cross-national comparisons of student performances. For instance, Jerrim, Oliver and Sims (2019) use the 2015 wave PISA data for England to investigate the relationship between students' achievement and the inquiry-based science teaching methodology. Zheng, Tucker-Drob and Briley (2018) examine how the family's and school's economic resources as well as the resources found at national level affect the association between science interest and science knowledge, using the 2015 PISA data. Applying the same dataset, S. Cumberworth and E. Cumberworth (2018) reveal if school socioeconomic composition is more strongly associated with standardized test scores among Lower-Socioeconomic Status students than it is among HigherSocioeconomic Status students. Based on PISA database 2015, Tang (2018) discloses that immigrant adolescents face lower life satisfaction compared to their non-immigrant counterparts, however this gap declines when specific school and family factors are taken into consideration.

Giambona and Porcu (2018) explain how Italian students' achievement is affected by school size, using PISA 2012 data. Yang and Ham (2017), adopting the same data, demonstrate how a well-established anti-discrimination legislation weakens the relationship between first- and second-generation immigrant students and school truancy. Sholderer (2017) utilize PISA 2015 database to explore the impact of social capital on the association between school autonomy and its performance. To inspect how intelligence (IQ) relates to happiness inequality and crime rates, Nikolaev and Salahodjaev (2016) and Burhan et. al. (2014), respectively, use two different databases whose common denominator is that the construction of IQ variable is based on distinct sources including PISA database. E. Erdogdu and F.Edrogdu (2015) show how home and school environment, access to ICT and student background influence students' academic achievements.

The present study is based on PISA 2015 data, when science was the subject of focus, and uses country level analysis. In this most recent cycle, the 2015 wave of PISA test, 72 participating countries were included for regional comparisons, but some countries are dropped in later analysis due to lacking data. Table 2 in Appendix lists all countries. The variable of interest is proxied by the students' performance in science. It is expressed in terms of mean score. Indicatively, students'

\footnotetext{
${ }^{11}$ More information about PISA is available at http://www.oecd.org/pisa/
} 
performance in science ranges from 331,639 to 555,575 score points. The available number of variables in this dataset that can be used as regressors are 167 in total and are classified into 14 categories. However, due to the limited number of observations, Principal Component Analysis is applied to reduce the dimensionality of the dataset, while retaining as much as possible of the variation present in it. The result is a new transformed set of variables, 43 in total, named as principal components, which are uncorrelated, and which are ordered so the first few retain most of the variation present in all the original variables (Jolliffe, 2002). Descriptive statistics for all the OECD variables used in this study are presented in Table 3 in the Appendix.

\subsection{Principal Component Analysis (PCA) - Technique}

The derivation of Principal Components (PCs) is based on the eigenvectors and eigenvalues of the covariance and/or correlation matrix. An important drawback of PCA based on covariance matrix is that PCs are sensitive to the units of measurement used for the regressors. Thus, before applying the dimensional reduction procedure for multivariate data, all the regressors are standardized because they come with different units. Table 4 in Appendix provides details regarding the new transformed set of variables, namely the principal components. Finally, to regress the dependent variables on this new set of regressors, all the dependent variables have been centered.

\section{Empirical Results}

Gini-BMA approach is employed to investigate how pre-primary education and other determinants affect students' performance, by calculating the weighted average of model specific estimates using Gini estimates ${ }^{12}$. The weights attached to each estimate is identical to posterior model probabilities. As a baseline estimation, a universe of all potential models using 43 covariates is taken into consideration. The results are compared to the OLS ones, taken by default when applying BMA methodology. Being totally agnostic about whether any of these regressors is included in the true model, a prior probability of 0.5 is attached to each one, implying a uniform model prior. Regarding the parameter space, the unit information prior (UIP) is adopted, where the integrated likelihood is proxied by the Schwarz Information Criterion (SIC).

Table 5 in Appendix displays the findings for the BMA analysis for the students' performance in science. The first column shows the posterior inclusion probability that each of the covariates is included in the truth model, while the second and the third columns present the BMA unconditional posterior mean (PSE) and posterior standard deviation (PSD) for each regressor. The remaining three columns provide, respectively, the same amount of information for the OLS case and for the

\footnotetext{
${ }^{12}$ An alternative extension for the calculation of the estimates can be found in Kourtellos, Stengos and Tan (2013), Durlauf, Kourtellos and Tan (2012) and Eicher, Lenkoski and Raftery (2009), who incorporate the 2SLS estimator into the BMA methodology.
} 


\section{DIMISKI Student Performance in Science}

other dependent variables. A covariate is identified as a "robust" determinant if the posterior inclusion probability exceeds $50 \%{ }^{13}$.

Referring to the first panel, of the 43 potential/promising candidate regressors only 13 affect the students' performance in science under the Gini analysis. The results grounded in Gini coefficients, suggest that "attendance in pre-primary education" (i.e., PC11) is a robust determinant of students' performance in science, with a posterior inclusion probability $81.6 \%$, but with an adverse effect on students' performance. However, this apparent negative result conceals the significant variation in years of pre-primary education. That is strongly reinforced by the finding that the "percentage of students who had not attended pre-primary education" (i.e., EducOut2) enters with high posterior inclusion probability, $73 \%$, and its marginal effect is substantial as well: on average, an one percent increase in no-attendance in pre-primary education reduces the performance by 10.45 score points. In other words, the apparent negative result of PC11 found earlier reflects the significant trade -offs that may exist between entering pre-primary education at a very early age and missing out on parental care at these very early ages, while it is clear that some pre-primary education is crucial and important, but not at all costs. There is a broad opinion in the sense that early early childhood education interventions provide a cognitively simulating environment that enhance school readiness, academic performance, social integration and long-term skill development (Myers (1995), Entwisle and Alexander (1993), Waldfogel (2002), Brooks-Gunn (2003), Carniero and Heckman (2003)). However, along with the early childhood interventions, many studies have found that home conditions are another crucial determinant of child's educational achievement (Bjorklund and Salvanes,2011). Both Velez et.al (1993) and Wößmann (2005) agree that, apart from preschool attendance, parental involvement and family features are key components in students' performance. A child's development begins within the family and depends on the parents' educational and cultural levels (Wößmann, 2005). Waldfogel and Washbrook (2011, and press b) support that parents that are educated and receive high income, spend more time to prepare their children's reading skills. In contrast, parents with lower income and less education have more possibilities to engage in harsh and incompatible parenting teaching behaviours that may negatively affect child's progress. Becker $(1981,1985)$ and Becker and Tomes (1986) embrace the theory of family to provide a reasonable justification for the failure of preschool education. Furthermore, the "percentage of students who had repeated a grade in primary, lower secondary or upper secondary school” (i.e., EducOut1), enters with a posterior inclusion probability, $53.8 \%$, but plays a positive role on the students' performance:

\footnotetext{
${ }^{13}$ In the paper " Trade Creation and Diversion Revisited: Accounting for model uncertainty and natural trading partner effects", Eicher, Henn and Papageorgiou (2012), following Kass and Raftery (1995), classified the strength of evidence of a regressors' effect into the following categories, sorted by the PIP: if PIP $<50 \%$, there is lack of evidence for the effect, if $50 \%<\mathrm{PIP}<75 \%$ there is weak evidence for the effect, if $75 \%<\mathrm{PIP}<95 \%$ there is positive evidence for the effect, $95 \%<\mathrm{PIP}<99 \%$ there is strong evidence for the effect, if $99 \%<\mathrm{PIP}<100 \%$ there is decisive evidence for the effect. These cut-offs form an approximation and are not based strictly in statistical theory.
} 
increasing EducOut 1 by $1 \%$ raises the probability that the performance will increase by 4.39 score points. The optimistic results about the effectiveness of grade retention can be supported by other studies (Alexander et. al. (1994), Karweit (1999), Lorence, Dworkin, Toenjes and Hill (2002), Greene and Winters (2004), Jacobs and Lefgren (2004), Eide and Goldhaber (2005), Lorence and Dworkin (2006)).

Additional robust determinants are also identified for students' performance in science. "Difference in science performance between immigrant and non-immigrant students" (i.e., PC110b) and the "mean ratio between students and classroom characteristics" (i.e., PC25a) affect performance distinctly. Both appear with a posterior inclusion probability above $90 \%$, (94\% and 93\% respectively) but with opposite impacts. While an increase in the PC110b coefficient adversely influences students' performance, an increase in the mean ratio is highly beneficial. "Expectations to work in science-related professional and technical occupations at age 30" (i.e., PC23a) exhibit important and negative effects on students' performance, with a posterior inclusion probability and a posterior mean equal to $78.8 \%$ and -11.63 respectively. In contrast, the "relative risk of boys expecting to work in science-related professional and technical occupations at age 30 " (i.e., PC33b) enters with an inclusion probability $77 \%$ and with a considerable positive coefficient equal to 18.04 .

The "number of students who are evaluated and assessed in alternative ways" (i.e., PC44), the "number of students with or without an immigrant background "(i.e., PC110a), the "number of science teachers who are qualified to teach science" (i.e., PC111a) and the "average time spent per week learning in regular science and no-science lessons" (i.e., PC25b), are four variables that are positively effective in performance, appearing with an posterior inclusion probability that ranges between $61 \%$ and $68 \%$ and posterior means that take values from 4.66 and 7.40 . Although PC25b enters positively, the average time spent after school in studying science and no-science lessons (i.e., PC17) has a negative impact and a posterior mean equal to 5.87. Surprisingly, the third Principal Component that refers to the category of the "number of students who are evaluated and assessed in alternative ways" (i.e., PC34) plays a negative role: it enters with an inclusion probability of $56 \%$, and a posterior mean equal to -4.73 .

A comparison between the Gini-MA results and the OLS-MA ones, presented in the second panel, suggests that the determinants that are important under Gini analysis are not necessarily similar to the ones that are important under OLS analysis. Of the 43 potential/promising candidate regressors only 10 affect the students' performance in science under OLS. The "number of students who refer skipping/arriving late at classes two weeks prior to the test" (i.e., PC26c), and the "difference in science performance" (i.e., PC39c) appear, under this case, to affect performance. Entering with posterior inclusion probabilities $78 \%$ and $71 \%$, respectively, with PC26c appear to have a negative effect, while PC39c appears to have a positive one. The "percentage of students who had not attend pre-primary education" (i.e., EducOut2) continues having a negative impact, although smaller ( 8.75 score points), with an inclusion probability of $84 \%$. This is similar to the 


\section{DIMISKI Student Performance in Science}

findings of the Gini-MA analysis, yet an important difference is that the effect of pre-primary education is not important with an inclusion probability less than $50 \%(0.31 \%)$. The case of "attendance in pre-primary education" (i.e., PC11) with the Gini-MA analysis was found to be strongly robust with a negative effect on students' performance and as was argued that apparent negative result may conceal the significant variation in years of pre-primary education and the potential benefits and costs between too many or too few years of pre-primary education. However, this is not the case for the "percentage of students who had repeated a grade in primary, lower secondary or upper secondary school" (i.e., EducOut1), which now appears with a negative posterior mean equal to -10.257 and much higher inclusion probability, $75 \%$. This is the most important difference so far since it implies that repeating a grade does not have a beneficial effect on performance.

The "number of students with or without an immigrant background" (i.e., PC110a) and the "mean ratio between students and classroom characteristics" (i.e., PC15a) enjoy strong posterior support for being important explanations for students' performance in science. Both receive an inclusion probability above $90 \%$, and their posterior means are of the same magnitude but of opposite signs: the PC15a coefficient is positive and equal to 16.629, while the PC110a coefficient is negative and equal to 16.699. It certainly appears to be true that "expectations to work in sciencerelated professional and technical occupations at age 30" (i.e., PC13a), the "relative risk of boys expecting to work in science-related professional and technical occupations at age 30" (i.e., $\mathrm{PC} 23 \mathrm{~b})$ and "average time spent per week learning in regular science and no-science lessons" (i.e., PC15b) contribute to science performance. The results found using Gini-MA approach are confirmed, since now, these variables enter with higher inclusion probabilities, $89 \%, 86 \%$ and $75 \%$ and with posterior means equal to $-14.292,22.123$ and 6.324 respectively. In contrast, the "number of students who are evaluated and assessed in alternative ways" (i.e., PC34) seems to positively affect performance and enters with an inclusion probability equal to $57 \%$ and a posterior mean equal to 3.87 .

Table 6 summarizes all the robust determinants under the Gini and OLS analysis, respectively. The first four regressors (i.e., the "number of students with or without an immigrant background" (i.e., PC110a), the "number of students who are evaluated and assessed in alternative ways" (i.e., PC34), the "percentage of students who had repeated a grade in primary, lower secondary or upper secondary school" (i.e., EducOut1), "percentage of students who had not attended preprimary education" (i.e., EducOut2)) appear to be significant under both analyses. Only the last variable retains the negative coefficient, while for the rest, the sign changes between the two cases. Regarding the next four variables (i.e. "mean ratio between students and classroom characteristics" (i.e., PC25a, PC15a), "average time spent per week learning in regular science and no-science lessons" (i.e., PC25b, PC15b), "expectations to work in science-related professional and technical occupations at age 30" (i.e., PC23a, PC13a), "relative risk of boys expecting to work in science-related professional and technical occupations at age 30" (i.e., 
PC33b, PC23b)), all appear to retain their sign but each variable refers to a different principal component, when comparing between the two analyses. The rest five variables that appear in the second column, are robust determinants only under the Gini analysis (i.e., "difference in science performance between immigrant and non-immigrant students" (i.e., PC110b), "attendance in preprimary education" (i.e., PC11), "average time spent after school in studying science and noscience lessons" (i.e., PC17), "number of students who are evaluated and assessed in alternative ways" (i.e., PC44), "number of science teachers who are qualified to teach science" (i.e., PC111a)), while the rest two variables that appear in the fourth column are robust determinants only under the OLS analysis (i.e., "difference in science performance" (i.e., PC39c), "number of students who refer skipping/arriving late at classes two weeks prior to the test" (i.e., PC26c)).

Image plots in figures 1a. and 1b. in Appendix demonstrate the sign and the importance of the regressors in the universe of models. These graphical representations highlight how the estimated coefficients fluctuate for the top 300 models shown in the horizontal axis, scaled by their posterior model probability. Blue and red colors indicate the inclusion of the regressor with a positive and negative posterior mean, respectively. White color indicates non-inclusion (or a zero coefficient). Robust covariates retain the same sign pretty much throughout the model space.

The first and third panel of figures $2 \mathrm{a}$. and $2 \mathrm{~b}$. in Appendix provide the distribution of model sizes for the baseline exercise for Students' performance in science. With $2^{\mathrm{K}}$ possible variable combinations, a uniform model prior implies a common prior model probability of 21.5. However, the graphs show a posterior model size distribution equal to 19.4231 and 19.0444, for the Gini and OLS case, respectively. The second and fourth panel of figures $2 \mathrm{a}$. and $2 \mathrm{~b}$. demonstrate the best 300 models encountered, ordered by their analytical posterior inclusion probability (red line) and plot their MCMC iteration counts (blue line) ${ }^{14}$. At 0.9367 and 0.7673 , these correlations are far from perfect but the differences from an exact likelihood approach are practically indiscernible and already indicate a satisfactory rate of convergence.

\section{Conclusions}

This paper identifies the robust determinants of students' performance in science. To ensure a comprehensive search, the analysis accounts for a rich set of possible regressors by employing Gini-BMA methodology. This approach constructs estimates that do not depend on a particular model specification, but rather they are conditional on the model space. A weighted average of Gini and OLS coefficients are calculated, respectively, where the weights are given by the posterior model probabilities.

Once model uncertainty is accounted for, the results can be summarized as follows. First, of the 43-promising candidate regressors only 13 affect the students' performance in science under the Gini analysis, while only 10 under OLS. Among the factors that are robust under both cases are:

\footnotetext{
${ }^{14}$ The model space is constructed by using birth-death MCMC sampler based on $10^{6}$ burn-ins and $5 \times 10^{6}$ draws.
} 
the "percentage of students who had not attend pre-primary education", the "percentage of students who had repeated a grade in primary, lower secondary or upper secondary school", the "mean ratio between students and classroom characteristics", the "expectations to work in science-related professional and technical occupations at age 30", the "relative risk of boys expecting to work in science-related professional and technical occupations at age 30", the "average time spent after school in studying science and no-science lessons" and the "number of students who are evaluated and assessed in alternative ways". However, in most cases, differences are observed in the signs of the coefficients.

Second, only under the OLS case, the "number of students who refer skipping/arriving late at classes two weeks prior to the test", the "difference in science performance" and the "number of students with or without an immigrant background" are considered important for the performance in science. In contrast, only under the Gini case, the "number of students who are evaluated and assessed in alternative ways", the "number of students with or without an immigrant background", the "number of science teachers who are qualified to teach science", the "difference in science performance between immigrant and non-immigrant students", the "average time spent per week learning in regular science and no-science lessons", and the "attendance in pre-primary education" affect performance.

\section{Appendix}

\subsection{Appendix A-Model Priors}

Beginning with considerations for choosing model priors, $\mathrm{p}\left(\mathrm{M}_{1}\right), \ldots, \mathrm{p}\left(\mathrm{M}_{\mathrm{k}}\right)$, the most common approach is an non-informative prior which favors all candidate models equally. For a model with $\mathrm{p}$ independently included regressors and size $\Xi$, the model size follows a Binomial distribution with probability of success $\xi$ :

$$
\Xi \sim \operatorname{Bin}(\mathrm{p}, \xi)
$$

where $p$ is the total number of candidate regressors and $\xi$ is the prior inclusion probability for each variable. Based on the above, the prior of a model $\mathrm{M}_{\mathrm{k}}$ with $\mathrm{p}_{\mathrm{k}}$ regressors is described by:

$$
p\left(M_{k}\right)=\xi^{q_{k}}(1-\xi)^{q-q_{k}}
$$

Raftery (1988), Raftery et al. (1997), Fernandez et al. (2001 a,b) and George and McCulloch (1993), fix $\xi$ to equal 0.5 so that every regressor has the same a priory probability ${ }^{15}$. This leads to

\footnotetext{
${ }^{15}$ Sala-i-Martin et al. (2004) perform sensitivity analysis to examine how different values for $\xi$ affect their results. They pre-specify a prior mean model size, kbar, implying that each variable has a prior probability of inclusion equal to $\mathrm{kbar} / \mathrm{K}$, with $\mathrm{K}$ being the total number of potential regressors. As a special case, when $\mathrm{kbar}=\mathrm{K} / 2$, equal probability is assigned to each possible model.
} 
the uniform model prior, which can be considered as a benchmark, that assigns equal prior probability to all models, implying that $\mathrm{p}\left(\mathrm{M}_{\mathrm{k}}\right)=2^{-p}$ for each $\mathrm{p}$ and that expected model size is $\mathrm{p} / 2$.

Mitchell and Beauchamp (1988) introduced the more general model prior structure, when prior information about the relevance of a variable is applicable, namely:

$$
p\left(M_{k}\right)=\prod_{j=1}^{q} \pi_{j}^{\delta_{k_{j}}}\left(1-\pi_{j}\right)^{1-\delta_{k_{j}}}
$$

where $\pi_{j} \varepsilon[0,1]$ is the prior probability that variable $\mathrm{X}_{\mathrm{j}}$ is included in the model and $\delta_{k_{j}}=1$ if $\mathrm{X}_{\mathrm{j}}$ is included in $\mathrm{M}_{\mathrm{k}}$ and 0 otherwise. Usually, it is assumed that $\pi_{\mathrm{j}}=\pi$ for $\mathrm{j}=1, \ldots$.,p. For $\pi=0.5$, (A.3) corresponds to a uniform prior across model space, while $\pi<0.5$ imposes a penalty for large models. Assigning $\pi_{j}=1$, guarantees the inclusion of variable $\mathrm{j}$ in all candidate models ${ }^{16}$. An extension on this approach was proposed by Brown et al (1998;2002) and Ley and Steel (2009), who assign a hyperprior on the probability of inclusion, $\pi$, converting it into a random variable drawn from a Beta distribution ${ }^{17}$.

When little information is available about the relative validity of the candidate models, assuming independent inclusion of regressors a priori seems a "neutral" choice ${ }^{18}$. However, it might be quarrelsome in some circumstances (Chipman et al. (2001)). The uniform model prior does not take into consideration interrelations between different variables, replicating a problem comparable to the irrelevance of independent alternatives (IIA) in the discrete-choice literature ${ }^{19}$. When the goal is to evaluate the relative significance of distinct theories and to define noninformative model priors across theories, the uniform prior is inappropriate, since the researcher can change the prior weights across theories simply by introducing "redundant" proxy variables for each theory.

George (1999b) proposed a dilution prior as a solution to the interrelations between variables. If the set of candidate regressors includes variables that represent the same concept, George's dilution prior increases the prior probabilities of models not containing these correlated predictors. However, this is not always the case, since variables are often measures of different ideas but are still correlated. Under this condition, the straightforward use of this prior penalizes larger models.

To deal with the interdependencies across theories due to the addition of "redundant" variables, Durlauf, Kourtellos and Tan $(2007 ; 2012)$ choose the prior probability that a particular theory defined as the set of variables that are used as proxies for that theory - is included in the true model to equal 0.5 . This assumption captures the non-informativeness (i.e. agnosticism) across theories

\footnotetext{
${ }^{16}$ George and McCulloch (1993), Volinsky et al. (1997), and Madigan and Raftery (1994) apply this approach in the context of linear regressions, Cox models, and graphical models, respectively.

${ }^{17}$ In that case, and according to Bernardo and Smith (1994, p.117), the prior on model size is a BinomialBeta distribution.

${ }^{18}$ Both the Binomial and the Binomial-Beta priors are based on this assumption.

${ }^{19}$ See Brock and Durlauf (2001), and Brock, Durlauf and West (2003) for further analysis.
} 


\section{DIMISKI Student Performance in Science}

but also ensures that the probability of inclusion of one theory in a model does not exclude other theories from being relevant. The question now is how to assign prior probabilities across the set of variables within each theory. To answer this, specification uncertainty should be taken into consideration. This problem is related to existence of correlations between potentially unrelated proxy regressors within theories. To handle this, they introduce a modified version of George's (1999b) dilution prior. Selecting a theory $\mathrm{T}$, with $\mathrm{p}_{\mathrm{T}}$ regressors, as a priori proper, they construct a binary vector $\gamma_{\mathrm{T}}$ for each possible combination of these $\mathrm{p}_{\mathrm{T}}$ proxies. The conditional prior probability assigned to each $\gamma_{\mathrm{T}}$ is given by:

$$
\mu^{D}\left(\gamma_{T}\right)=\left|R_{\gamma_{T}}\right| \prod_{j=1}^{q_{T}} \pi_{j}^{\gamma_{i}}\left(1-\pi_{j}\right)^{1-\gamma_{j}}
$$

where $\pi_{j}$ is the prior inclusion probability of each proxy variable in theory $\mathrm{T}$, which is equal to $\pi_{j}=0.5$ for $\mathrm{j}=1, \ldots, \mathrm{p}_{\mathrm{T}}$ and $\left|R_{\gamma_{T}}\right|$ is the correlation matrix for the set of variables included in the binary vector $\gamma_{T}$. When regressors are collinear, $\left|R_{\gamma_{T}}\right|$ takes the value of zero, whereas when regressors are orthogonal, it is equal to 1 . This structure penalizes models that include irrelevant variables and retains weights on informative models.

A similar approach can be found in Brock and Durlauf (2001) and Brock et al. (2003) who focus on economic theories rather than individual regressors and use hierarchical tree structure to construct model priors. A related idea was expressed by Chipman et al. (2001), who assigns probability to neighborhoods of similar models. More recently, George (2010) develops dilution model priors classified in three distinct approaches: the tessellation defined dilution priors ${ }^{20}$, the collinearity adjusted ones and the model distance based. The key characteristic of these is to assign prior probabilities more uniformly across neighborhoods of models rather across models ${ }^{21}$.

Despite it seems a sufficient answer to the dilution property, this prior structure obliges a decision on which proxies are classified under a specific theory and which models belong to the same neighborhood. Such decisions are not within reach in most of the cases.

\subsection{Parameter priors/Prior distributions of parameters}

In the context of Bayesian framework, to complete the Normal linear regression model described in (2), a prior distribution for the parameters $\theta_{\mathrm{k}}=\left(\beta_{0}, \beta^{(\mathrm{k})}, \sigma\right)$ is needed. This distribution will be given through a density function:

$$
p\left(\beta_{o}, \beta^{(k)}, \sigma \mid M_{k}\right)
$$

which consists a key component in the marginal or integrated likelihood of model $\mathrm{M}_{\mathrm{k}}$ :

\footnotetext{
${ }^{20}$ Moser and Hofmarcher (2014) provide an extended analysis on the implementation of this approach.

${ }^{21}$ Another promising approach to dilution prior construction is suggested by Garthwaite and Mubwandarikwa (2010), who construct prior model weights using the correlation matrix between models. This matrix reflects the similarities between models and assigns small weights to those who are highly correlated.
} 
Review of Economic Analysis 13 (2021) 157-211

$$
p\left(D \mid M_{k}\right)=\int p\left(D \mid \beta_{o}, \beta^{(k)}, \sigma, M_{k}\right) p\left(\beta_{o}, \beta^{(k)}, \sigma \mid M_{k}\right) d \beta_{o} d \beta^{(k)} d \sigma
$$

and affects right away the posterior model probabilities $p\left(M_{k} \mid D\right)$. Two challenging questions arise regarding the computation of $p\left(M_{k} \mid D\right)$ and the influence of the assumptions made for prior distributions on the latter quantity. Analytical answer to the first one is provided in the next section.

Apart from purely computational features, the choice of "rational" prior parameter distributions remains unresolved and depends mainly on the availability of prior information. When information about the parameters is given, informative priors can be constructed (e.g. Jackman and Western (1994)). However, under little or absence of prior information, choosing a distribution/density for (13) is a very complex task. Consequently, many efforts have been made to establish "default priors" or "reference priors" that can be applied in all such cases.

\subsubsection{A non-informative prior for the intercept and for $\sigma$}

Following Fernandez et al. (2001b), "non-informative" improper priors have been adopted for the common intercept and the scale $\sigma$, such

$$
\begin{aligned}
& p\left(\beta_{o}\right) \propto 1 \\
& p(\sigma) \propto \sigma^{-1}
\end{aligned}
$$

assuming common prior distribution for $\sigma$ across models and that $\beta_{0}$ is independent of $\beta^{(\mathrm{k})}$ and $\sigma$, so that $\mathrm{p}\left(\beta_{0}, \beta^{(\mathrm{k})}, \sigma\right)=\mathrm{p}\left(\beta_{o}\right) \mathrm{p}\left(\beta^{(k)} \mid \sigma^{2}\right) \mathrm{p}\left(\sigma^{2}\right)$.

\subsubsection{Informative priors for the regression coefficients}

In general, direct use of improper noninformative priors for model-specific parameters is not allowable because their arbitrary norming constants remain in the integrated likelihoods and lead to uncertain model probabilities ${ }^{22}$ (Jeffreys (1961); Berger and Pericchi (2001)). Conventional proper priors for regression coefficients have been relied on the natural-conjugate approach, which assigns a conditional normal prior on the k-th model's parameter $\left(\beta^{(\mathrm{k})} \mid \sigma^{2}\right)$ with zero mean and the variance proposed by Zellner (1986), leading to the following prior distribution (Fernandez et al. (2001b)):

$$
p\left(\beta_{o}, \beta^{(j)}, \sigma \mid M_{j}\right) \propto \sigma^{-1} f_{N}^{k_{j}}\left(\beta^{(j)} \mid 0, \sigma^{2}\left(g Z_{j}^{\prime} Z_{k}\right)^{-1}\right)
$$

where $f_{N}^{q}(\mathrm{w} \mid \mathrm{m}, \mathrm{V})$ denotes the density function of a q-dimensional Normal-distribution of $\mathrm{w}$ with mean $\mathrm{m}$ and covariance matrix $\mathrm{V}$, and $\mathrm{g}$ is a scalar that measures how important are the prior beliefs

\footnotetext{
${ }^{22}$ To overcome this problem, Berger and Pericchi (1996) and O’Hagan (1995) apply intrinsic Bayes factors and fractional Bayes factors, respectively, but their approaches suffer from inconsistencies.
} 


\section{DIMISKI Student Performance in Science}

of the researcher ${ }^{23}$. The above prior distribution allows for exclusion of regressors from some of the models, represented by a prior point mass at zero (known as the "spike-and-slab" approach in Mitchell and Beauchamp (1988)).

Efficiently, the thorny problem of picking a prior distribution for $\beta$ can be solved only by selecting a single parameter g. Under this "benchmark" prior structure, incorporating subjective prior knowledge into the analysis is not feasible or desirable, resulting in little influence on posterior inference. These "automatic" priors depend only on the number of independent variables and the sample size (Fernandez et al. (2001b)). In the same spirit, Kass and Wasserman (1995 and Raftery (1995) recommend "unit information" priors, which contain the same amount of information as a regular single observation. In contrast, Raftery et al. (1997) display "weakly informative" proper priors, which are data dependent through the response variable ${ }^{24}$.

To demonstrate the behavior of several notorious priors that belong to the above-mentioned categories (refer to the priors 1-11 and 14, presented in Table1 in Appendix), Eicher et all. (2007) compare their predictive performance by employing growth and simulated data and conclude that Unit information Prior in combination with uniform model prior surpass all the rest. In contrast, Ley and Steel (2009) recommend the avoidance of UIP in the context of growth regressions or under the presence of large number of potential regressors, proposing instead the use of prior $\mathrm{g}=1 / \mathrm{k}^{2}$ (combined with the assumption that the inclusion of each regressor is independent and equal to 0.5 ).

According to Liang et al. (2008), when fixed g priors are used to construct Bayes factors, the result might suffer from the Bartlett's and the Information paradoxes. To overcome this complication, they investigate fully Bayes approaches and suggest three alternatives: Global and Local empirical Bayes procedures, the multivariate Zellner-Siow Cauchy priors (initially introduced by Zellner and Siow (1980)) and a family of prior-probabilities imposed on $\mathrm{g}^{25}$. Because this hyper-g prior family for g lacks model selection consistency, they provide a modification, known as hyper-g/n prior family ${ }^{26}$. In the same strand of literature, Ley and Steel (2012) attach a proper hyperprior to $\mathrm{g}$, which corresponds to a shrinkage factor $\delta=\mathrm{g} /(1+\mathrm{g})$ that follows a Beta prior distribution. This "benchmark" Beta prior with $\mathrm{c}=0.1$ and a hyper-g/n prior with $\alpha=3$ (and

\footnotetext{
${ }^{23}$ A large value of $g$ implies a small true model, that is, many of the regressors equal zero, while a small $g$ supports the existence of a large model. When $g \rightarrow 0$, the $\beta$ estimator is the Least Squares estimator of the full/ "kitchen sink" model (George and Foster (2000)-Calibration and empirical Bayes variable selection).

${ }^{24}$ Tobias and $\mathrm{Li}$ (2004) apply this prior choosing the following values for the parameters: $\mathrm{V}=2.85^{2} \mathrm{I}_{\mathrm{k}}, \lambda=0.28$, $\mathrm{v}=2.58, \mu_{\beta}=0$.

${ }^{25}$ Strawderman (1971)-Proper Bayes minimax estimators of the multivariate normal mean- and Cui and George (2007)-Empirical Bayes vs Fully Bayes variable selection- study priors that belong to this family of prior probabilities for $\mathrm{g}$.

${ }^{26}$ According to Liang et al. (2008), the three alternative solutions resolve the information paradox and are consistent under prediction. However, only Zellner-Siow priors are consistent for model selection.
} 
$\alpha=4$ ), is compared with existing priors ${ }^{27}$ in terms of model selection consistency, avoidance of information paradox and empirical behavior/performance.

Feldkircher and Zeugner (2009) finalize the analysis presented by Liang et al. (2008), by adding the posterior distribution of $\beta \mid y, X$, its second moments, and the second moment of the shrinkage factor. Regarding the computation of these posterior expressions, they use algebraic transformations and implement accurate statistics to overcome possible errors that occur when Laplace approximations are applied. In a simulation study with noisy data, they show that hyper gprior spreads the posterior mass more evenly among the candidate models compared to the "Benchmark prior" (FLS (2001b)).

A completely different approach, known as the Bayesian Averaging of Classical Estimates (BACE) methodology, is given by Sala-i-Martin et al. (2004), whose analysis is not based on gparameter priors, but rather information is extracted from the data and the final estimates are the result of averaging OLS estimates across models. The weights assigned to each model is the logarithm of the likelihood function, agreeing to Schwarz model selection criterion ${ }^{28}$.

\footnotetext{
${ }^{27}$ These are Zellner and Siow (1980), Maruyama-George (2011), Bottolo-Richardson (2008), Feldkircher and Zeugner (2009), Liang et al. (2008), Carvalho et al. (2010), Forte et al. (2010).

${ }^{28}$ Although Sala-i-Martin et al. support that "BACE limits the effect of prior information", it is important to mention that even if prior assumptions are implicit now, this does not imply that the dependence on them becomes less important (Ley and Steel (2009)).
} 
DIMISKI Student Performance in Science

\subsection{Appendix B-Figures}

Figure 1: Model Inclusion Probability on Best 300 Models for the Gini case (top) and OLS case (bottom)

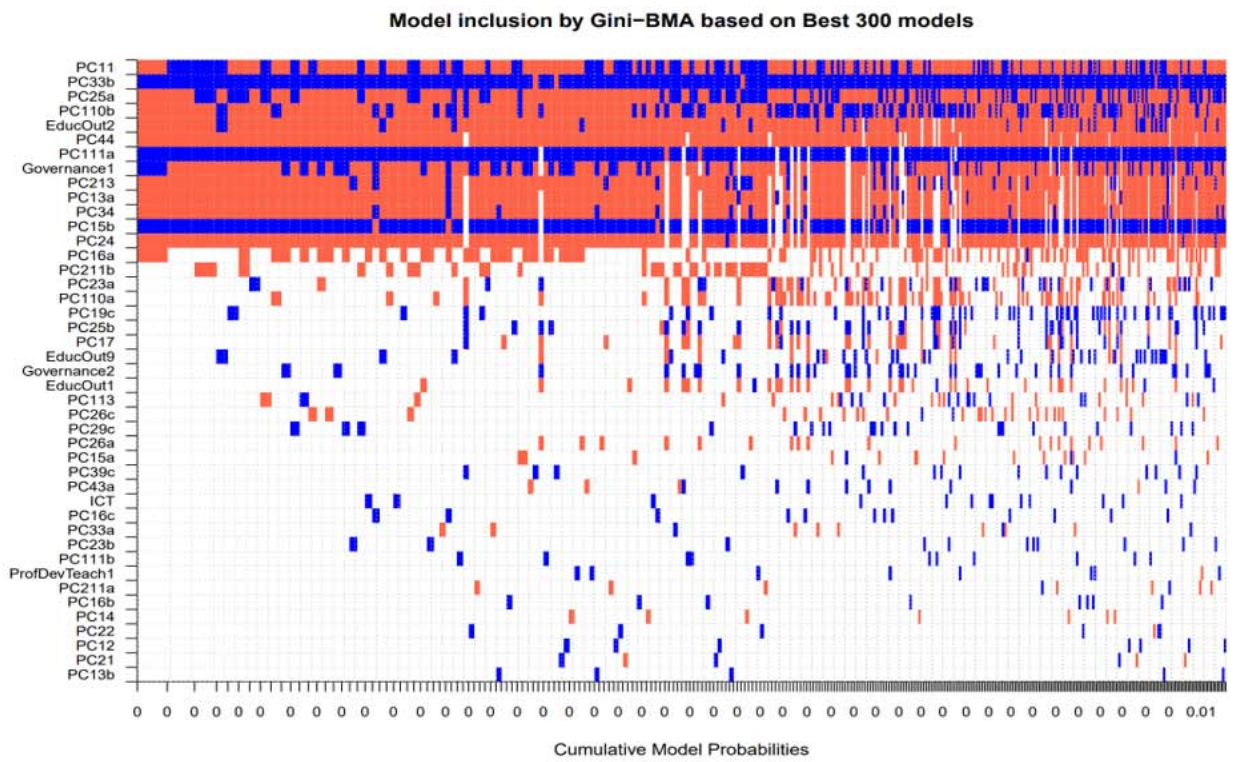

Model inclusion by OLS-BMA based on Best $\mathbf{3 0 0}$ models

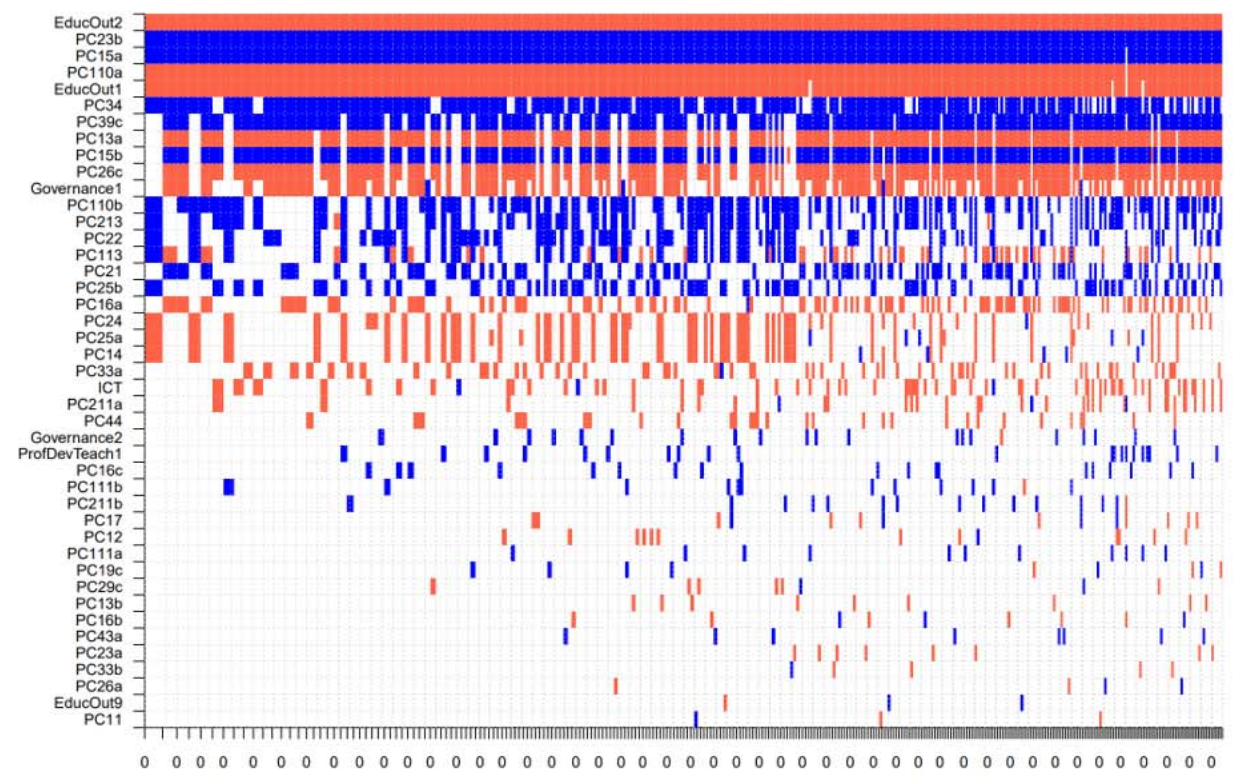

Cumulative Model Probabilities 
Review of Economic Analysis 13 (2021) 157-211

Figure 2: Posterior Model Size Distribution and Posterior Model Probabilities for the Gini case (top) and OLS case (bottom)

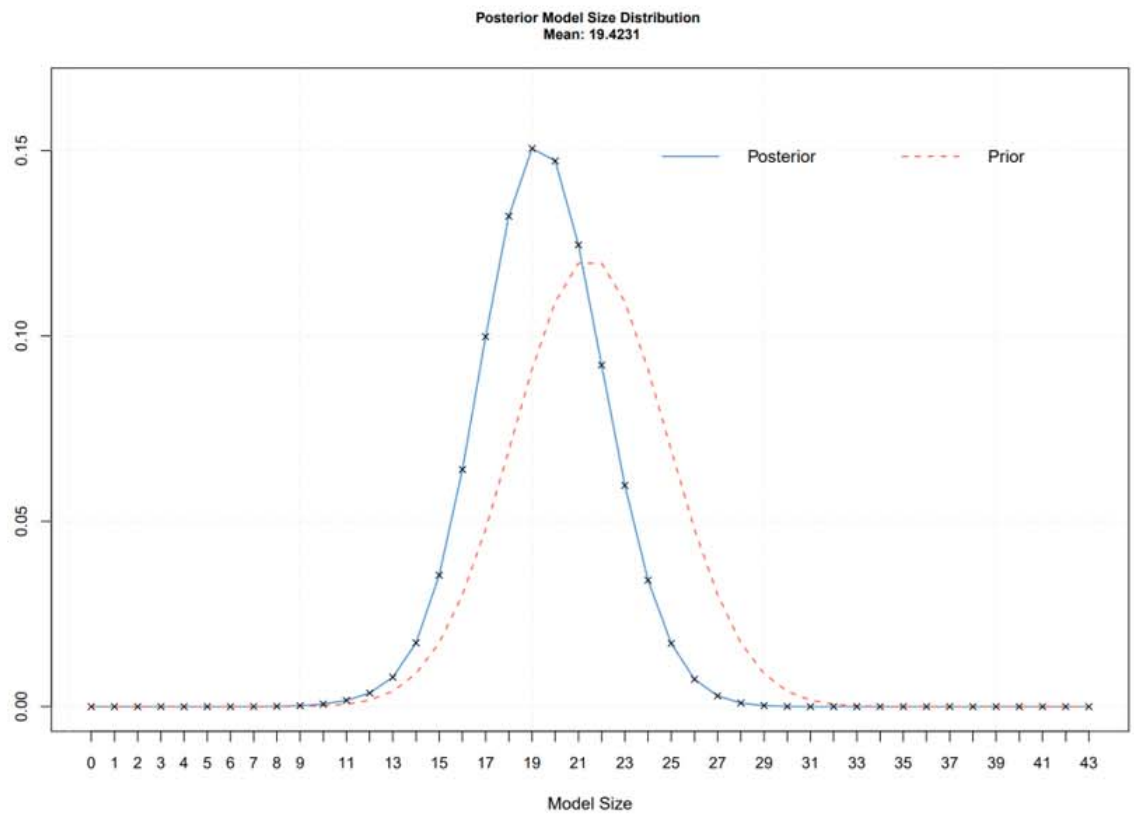

Posterior Model Probabilities

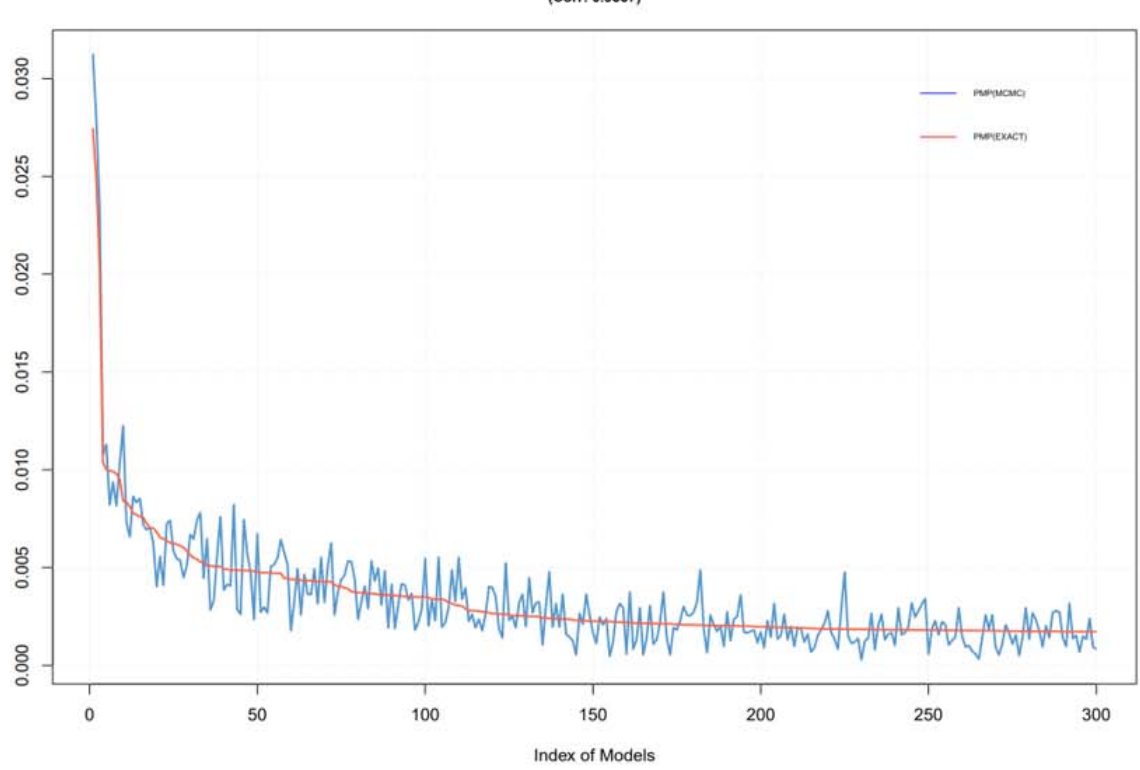


DIMISKI Student Performance in Science
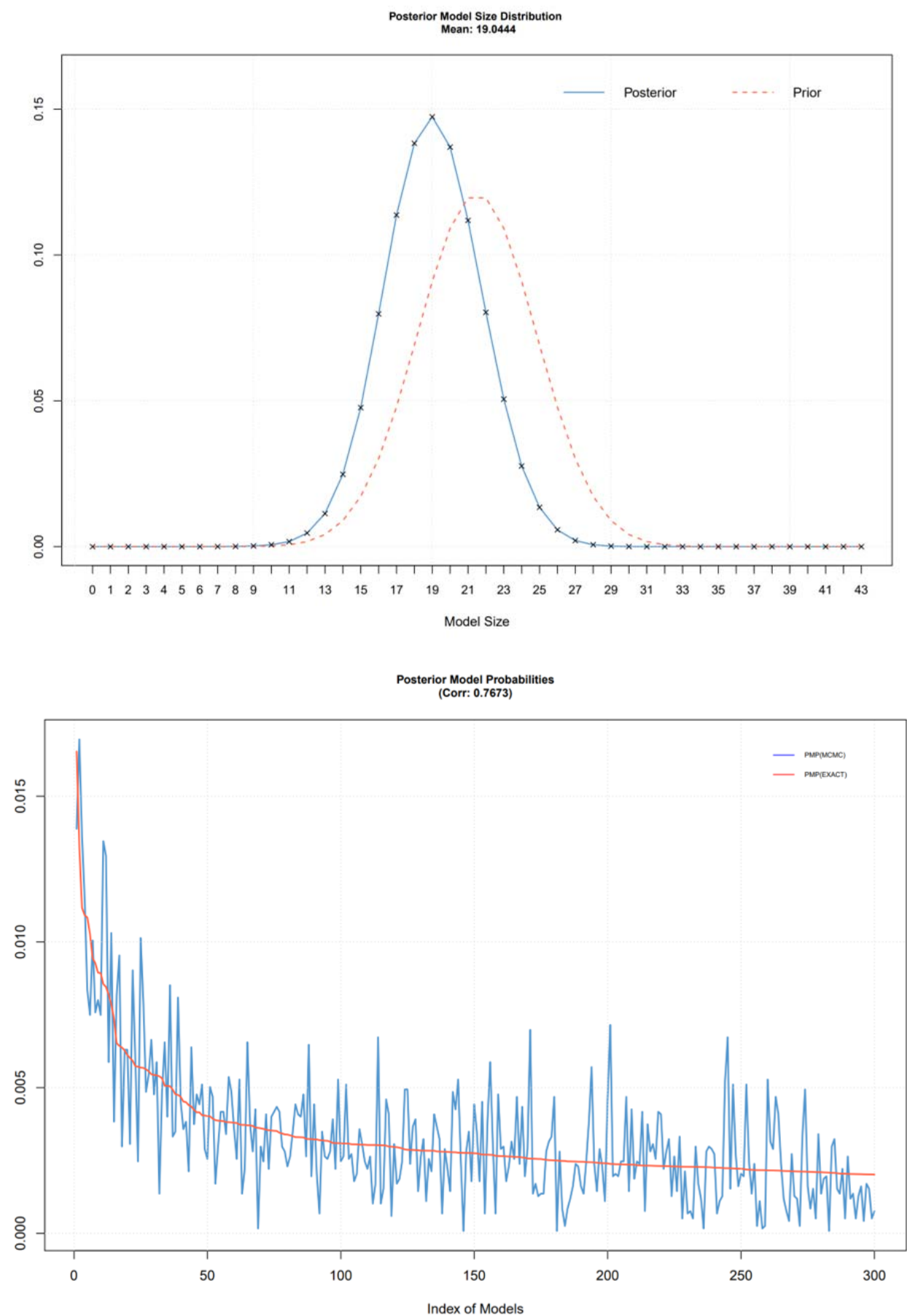
Review of Economic Analysis 13 (2021) 157-211

\subsection{Appendix C-Table}

Table 1: Parameter prior structures

\begin{tabular}{|c|c|c|}
\hline \multicolumn{3}{|c|}{ Automatic Priors (Fernandez et al. (2001b) (FLS)) } \\
\hline G-prior & & Description \\
\hline 1) $g_{o j}=\frac{1}{n}$ & $\begin{array}{l}\text { The log Bayes factor obtained under } \\
\text { this prior behaves asymptotically like } \\
\text { the Schwarz criterion. } \\
\text { This prior leads to consistency. }\end{array}$ & $\begin{array}{l}\text { It assigns the same amount } \\
\text { of information as a regular } \\
\text { single observation. It is } \\
\text { like "unit information } \\
\text { prior" proposed by Kass } \\
\text { and Wasserman (1995), } \\
\text { but with zero mean instead } \\
\text { of MLE. }\end{array}$ \\
\hline 2) $g_{o i}=\frac{k_{j}}{n}$ & $\begin{array}{l}\text { The log Bayes factor obtained under } \\
\text { this prior behaves asymptotically like } \\
\text { the Schwarz criterion. } \\
\text { This prior leads to consistency. }\end{array}$ & $\begin{array}{l}\text { As more independent } \\
\text { variables are added in the } \\
\text { model, more information } \\
\text { is attached to this prior } \\
\text { (i.e. the discrete point } \\
\text { mass at zero for } \beta \text { shrinks.) }\end{array}$ \\
\hline 3) $g_{o i}=\frac{k^{\frac{1}{k_{j}}}}{n}$ & $\begin{array}{l}\text { The log Bayes factor obtained under } \\
\text { this prior behaves asymptotically like } \\
\text { the Schwarz criterion. } \\
\text { This prior leads to consistency. }\end{array}$ & $\begin{array}{l}\text { As more independent } \\
\text { variables are added in the } \\
\text { model, less information is } \\
\text { attached to this prior. }\end{array}$ \\
\hline 4) $g_{o i}=\sqrt{\frac{1}{n}}$ & $\begin{array}{l}\text { The penalty applied for selecting } \\
\text { larger models is smaller compared to } \\
\text { the Schwarz (BIC) criterion. } \\
\text { This prior leads to consistency. }\end{array}$ & $\begin{array}{lr}\text { It is an in-between case of } \\
\text { prior } 1 \text { and attributes } \\
\text { smaller } & \text { asymptotic } \\
\text { penalty for } & \text { selecting } \\
\text { larger models. } & \end{array}$ \\
\hline 5) $g_{o i}=\sqrt{\frac{k_{j}}{n}}$ & $\begin{array}{l}\text { The penalty applied for selecting } \\
\text { larger models is smaller compared to } \\
\text { the Schwarz (BIC) criterion. } \\
\text { This prior leads to consistency. }\end{array}$ & $\begin{array}{l}\text { It is an in-between case of } \\
\text { prior } 2 \text {, more information } \\
\text { is attached to this prior as } \\
\text { the number of regressors } \\
\text { increases (i.e. the discrete } \\
\text { point mass at zero for } \beta \\
\text { shrinks). }\end{array}$ \\
\hline 6) $g_{o i}=\frac{1}{(\operatorname{Ln}(n))^{3}}$ & This prior leads to consistency. & $\begin{array}{l}\text { As } \mathrm{n} \text { becomes large, this } \\
\text { prior mimics the Hannan- } \\
\text { Quinn (1979) criterion } \\
\text { with } \mathrm{C}_{\mathrm{HQ}}=3 \text {. }\end{array}$ \\
\hline 7) $g_{o i}=\frac{\operatorname{Ln}\left(k_{j}+1\right)}{\operatorname{Ln}(n)}$ & This prior leads to consistency. & $\begin{array}{l}\text { As n becomes larger, this } \\
\text { prior decreases even } \\
\text { slower and has asymptotic } \\
\text { convergence to the } \\
\text { Hannan-Quinn (1979) } \\
\text { criterion with } \mathrm{CHQ}_{\mathrm{HQ}}=1 .\end{array}$ \\
\hline 8) $g_{o i}=\frac{\delta \gamma^{1 / k_{j}}}{\left(1-\delta \gamma^{1 / k_{j}}\right)}$ & $\begin{array}{l}\text { This prior does not lead to consistency } \\
\text { in general. }\end{array}$ & $\begin{array}{l}\text { This natural conjugate } \\
\text { prior structure is proposed } \\
\text { by Laud and Ibrahim } \\
\text { (1996) and is subjectively } \\
\text { elicited through predictive } \\
\text { implications. The }\end{array}$ \\
\hline
\end{tabular}


DIMISKI Student Performance in Science

\begin{tabular}{|c|c|c|}
\hline & & $\begin{array}{l}\text { suggested values for the } \\
\text { parameters are: } \gamma<1 \text {, such } \\
\text { that the prior increases } \\
\text { when more regressors } \mathrm{k}_{\mathrm{j}} \\
\text { are added in the model, the } \\
\text { shrinkage factor } \delta= \\
\mathrm{g}_{0 \mathrm{j}} /\left(1+\mathrm{g}_{0 \mathrm{j}}\right) \text { belongs to the } \\
\text { interval [0.10,0.15] (i.e. } \\
\text { the weight of the " prior } \\
\text { prediction error" in the } \\
\text { Bayes factors) and the } \\
\text { number of regressors } \mathrm{k}_{\mathrm{j}} \\
\text { ranges between } 1 \text { and } 15 . \\
\text { To cover this interval, } \\
\text { FLS choose the values } \\
\gamma=0.65 \text { and } \delta=0.15\end{array}$ \\
\hline 9) $g_{o i}=\frac{1}{k^{2}}$ & $\begin{array}{l}\text { This prior does not lead to consistency } \\
\text { in general. }\end{array}$ & $\begin{array}{l}\text { It coincides with the Risk } \\
\text { Inflation Criterion } \\
\text { proposed by Foster and } \\
\text { George (1994) }\end{array}$ \\
\hline 10) $g_{o i}=\frac{1}{\max \left\{n, k^{2}\right\}}$ & $\begin{array}{l}\text { This prior combines the consistent } \\
\text { Bayes factors shaped under prior } 1 \\
\text { with the remarkable small sample } \\
\text { performance of prior } 9 \text {. }\end{array}$ & $\begin{array}{l}\text { It is a combination of prior } \\
1 \text { and prior } 9 \text { and is the } \\
\text { most preferred prior for } \\
\text { FLS }(2001 \mathrm{~b})\end{array}$ \\
\hline \multicolumn{3}{|c|}{ Unit Information prior (Kass and Wasserman (1995); Raftery (1995)) } \\
\hline 11) $g=N(g-U I P)$ & $\begin{array}{l}\text { This prior is known as g-UIP. } \\
\text { The posterior model probabilities (and } \\
\text { thus the Bayes factors) are } \\
\text { approximated by the Schwarz criterion } \\
\text { (BIC). That is, } \\
\log \operatorname{pr}\left(\mathrm{D} \mid \mathrm{M}_{\mathrm{k}}\right) \approx \mathrm{c}-1 / 2 \mathrm{BIC} \mathrm{C}_{\mathrm{k}} \\
\text { where } \mathrm{BIC} \mathrm{C}_{\mathrm{k}}=\mathrm{n} \log \left(1-\mathrm{R}_{\mathrm{k}}{ }^{2}\right)+\mathrm{p}_{\mathrm{k}} \log (\mathrm{n}) \\
\mathrm{c} \text { is a constant that does not change } \\
\text { across models } \\
\text { The g-UIP prior does not resolve the } \\
\text { information paradox. }\end{array}$ & $\begin{array}{l}\text { It assigns the same amount } \\
\text { of information as a regular } \\
\text { single observation. }\end{array}$ \\
\hline
\end{tabular}


Review of Economic Analysis 13 (2021) 157-212

\begin{tabular}{|c|c|c|}
\hline \multicolumn{3}{|c|}{ Foster and George (1994) } \\
\hline 12) $g=q^{2}(\mathrm{~g}-\mathrm{RIC})$ & $\begin{array}{l}\text { This prior is known as g-RIC. } \\
\text { The g-RIC prior does not resolve the } \\
\text { information paradox. }\end{array}$ & $\begin{array}{l}\text { It is related to Risk } \\
\text { inflation Criterion (RIC) }\end{array}$ \\
\hline 13$) g=\max \left\{N, q^{2}\right\}(\mathrm{g}-\mathrm{BRIC})$ & $\begin{array}{l}\text { This prior is known as the } \\
\text { "Benchmark prior" and it is called the } \\
\text { "g-BRIC". Regarding predictive } \\
\text { performance, it is the most favorite by } \\
\text { FLS (2001b). } \\
\text { The g-BRIC prior does not resolve the } \\
\text { information paradox. }\end{array}$ & $\begin{array}{l}\text { It is a combination of prior } \\
11 \text { and prior } 12 .\end{array}$ \\
\hline \multicolumn{3}{|c|}{$\begin{array}{c}\text { "Weakly-informative" priors or equivalently "Data-Dependent" priors (Raftery, Madigan } \\
\text { and Hoeting (1997)) }\end{array}$} \\
\hline $\begin{array}{l}\text { 14) } \\
B \sim N\left(\mu, \sigma^{2} V\right) \\
\text { where } \\
V=\sigma^{2} \varphi^{2}\left(\frac{1}{n X^{\prime} X}\right)^{-1} \frac{u \lambda}{\sigma^{2}} \sim \chi^{2}\end{array}$ & $\begin{array}{l}\text { This prior belongs to standard normal } \\
\text { gamma conjugate class of priors. } \\
\text { The hyperparameters to be selected } \\
\text { are: } \mathrm{v}, \lambda, \mu(\mathrm{a}(\mathrm{p}+1) \text { vector) and } \mathrm{V}(\mathrm{a} \\
(\mathrm{p}+1) \mathrm{x}(\mathrm{p}+1) \text { covariance matrix for } \beta \\
\left.\text { referring to model } \mathrm{M}_{\mathrm{k}}\right) \\
\text { The marginal likelihood for } \mathrm{Y} \text { is: } \\
p\left(Y \mid \mu_{i}, V_{i}, x_{i}, M_{i}\right)=\frac{\Gamma\left(\frac{v+n}{2}\right)(v \lambda)^{v / 2}}{\pi^{\frac{n}{2}} \Gamma\left(\frac{v}{2}\right)\left|I+X_{i} v_{i} x_{i}^{t}\right|^{\frac{1}{2}}} x \\
x\left[\lambda v+\left(Y-x_{i} \mu_{i}\right)^{t} x\left(I+x_{i} v_{i} x_{i}^{t}\right)^{-1}(Y\right. \\
\left.\left.\qquad-x_{i} \mu_{i}\right)\right]^{-(v+n) / 2} \\
\text { The Bayes factor for model } \mathrm{M}_{0} \text { versus } \\
\text { model } \mathrm{M}_{1} \text { is: } \\
B_{o i}=\left(\frac{\left|I+x_{1} v_{1} x_{1}^{t}\right|}{\left|I+x_{0} v_{0} x_{0}^{t}\right|}\right)^{1 / 2}\left(\frac{a_{0}}{a_{1}}\right)^{-(v+2) / 2}\end{array}$ & $\begin{array}{l}\text { It is defined by four } \\
\text { hyperparameters: if the } \\
\text { full model has an } \mathrm{R}^{2} \text { less } \\
\text { than } 0.9 \text { then } \varphi=0.85, \mathrm{v}= \\
2.58, \lambda=0.28 \text {. In contrast, } \\
\text { if the full model has an } \mathrm{R}^{2} \\
\text { more than } 0.9 \text { then } \varphi=9.2 \text {, } \\
\mathrm{v}=0.2, \lambda=0.1684 \text {. }\end{array}$ \\
\hline \multicolumn{3}{|c|}{ Hyper -g priors (Liang, Paulo, Molina, Clyde and Berger (2008)) } \\
\hline 15) $\pi(g)=\frac{(n / 2)^{1 / 2}}{\Gamma(1 / 2)} g^{-3 / 2} e^{-n / 2 g}$ & $\begin{array}{l}\text { To analyze the properties of priors on } \\
\text { g, a quantity, named as shrinkage } \\
\text { factor, is used and defined as: } \\
\qquad \delta=\frac{g}{(1+g)} \\
\text { following a distribution: }\end{array}$ & $\begin{array}{l}\text { These are the multivariate } \\
\text { Cauchy priors, introduced } \\
\text { by Zellner and Siow } \\
(1980) \text {, where the prior on } \\
\mathrm{g} \text { follows an Inverse } \\
\text { Gamma (1/2, } \mathrm{n} / 2) \\
\text { distribution. }\end{array}$ \\
\hline
\end{tabular}


DIMISKI Student Performance in Science

\begin{tabular}{|c|c|c|}
\hline & 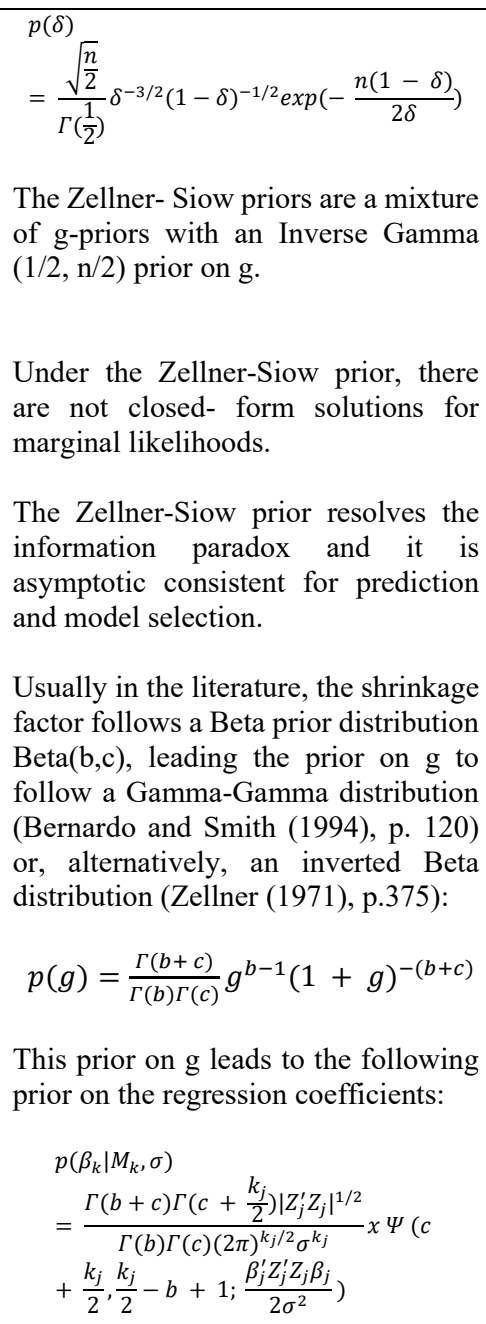 & \\
\hline $\begin{array}{l}\text { 16) } \\
\pi(g)=\frac{a-2}{2}(1+g)^{-a / 2} \\
\text { with } g>0, a>2\end{array}$ & $\begin{array}{l}\text { To analyze the properties of priors on } \\
\mathrm{g} \text {, the shrinkage factor } \\
\delta=\mathrm{g} /(1+\mathrm{g}) \text { is mobilized, which } \\
\text { follows a Beta distribution } \\
\text { Beta }(\mathrm{b}, \mathrm{c})=\operatorname{Beta}(1,(\alpha / 2)-1), \alpha>2 \text {. For } \\
\alpha=4 \text { it becomes a uniform } \\
\text { distribution. Any choice between } \\
2<\alpha \leq 4 \text { might give reasonable results. } \\
\text { Liang et al. (2008) choose the values } \\
\alpha=3 \text { and } \alpha=4 \text {. } \\
\text { The posterior distribution of } \mathrm{g} \text { under } \\
\text { model Mk has a closed-form solution } \\
\text { given by: }\end{array}$ & $\begin{array}{l}\text { This is a family of hyper-g } \\
\text { priors proposed by Liang } \\
\text { et al. (2008). }\end{array}$ \\
\hline
\end{tabular}


Review of Economic Analysis 13 (2021) 157-212

\begin{tabular}{|c|c|c|}
\hline & $\begin{array}{l}\quad \begin{array}{l}p\left(g \mid M_{k}\right) \\
\quad=\frac{p_{k}+a-2}{2_{2} F_{1}\left((n-1) / 2 ; 1 ;\left(p_{k}+a\right) / 2 ; R_{k}^{2}\right)} x \\
(1+g)^{\left(n-1-p_{k}-a\right) / 2}\left[1+\left(1-R_{k}^{2}\right) g\right]^{-(n-1) / 2}\end{array} \\
\text { The hyper-g prior derived from this } \\
\text { family resolves the information } \\
\text { paradox, under the constraint that } 2<\alpha \\
\leq 3 \text { (when sample size is minimal). } \\
\text { Also, it is asymptotic consistent for } \\
\text { prediction but not for model selection. }\end{array}$ & \\
\hline 17) $\pi(g)=\frac{a-2}{2 n}\left(1+\frac{g}{n}\right)^{-a / 2}$ & $\begin{array}{l}\text { The shrinkage factor } \delta=\mathrm{g} /(\mathrm{n}+\mathrm{g}) \\
\text { follows a Beta distribution Beta }(\mathrm{b}, \mathrm{c})= \\
\text { Beta }(1,(\mathrm{a} / 2)-1) \\
\text { This family of hyper- } \mathrm{g} / \mathrm{n} \text { priors } \\
\text { resolves the asymptotic inconsistency } \\
\text { faced by the hyper- } \mathrm{g} \text { priors in } 16 \text {. }\end{array}$ & $\begin{array}{l}\text { This is a family of } \\
\text { modified hyper-g/n priors } \\
\text { proposed by Liang et al. } \\
(2008) \text {. }\end{array}$ \\
\hline $\begin{array}{r}\text { 18) } g_{\gamma}^{E B L}=\max \left\{F_{\gamma}-1,0\right\} \\
F_{\gamma}=\frac{R_{\gamma}^{2} / p_{\gamma}}{\left(1-R_{\gamma}^{2}\right) /\left(n-1-p_{\gamma}\right)}\end{array}$ & $\begin{array}{l}\text { This g-prior is based on the Local } \\
\text { Empirical Bayes approach. } \\
\text { This g-prior resolves the information } \\
\text { paradox and is asymptotic consistent } \\
\text { for prediction. However, it is not } \\
\text { consistent for model selection. }\end{array}$ & $\begin{array}{l}\text { A distinct g-prior is } \\
\text { evaluated for each model. } \\
\text { The estimate for g } \\
\text { coincides with the } \\
\text { maximum marginal } \\
\text { likelihood estimate, under } \\
\text { the restriction to be a } \\
\text { positive number. }\end{array}$ \\
\hline $\begin{array}{l}\text { 19) } \\
g^{E B G} \\
=\operatorname{argmax}_{g>0} \sum_{\gamma} p\left(M_{\gamma}\right) \frac{(1+g)^{\left(n-p_{\gamma}-1\right) /}}{\left[1+g\left(1-R_{\gamma}^{2}\right)\right]^{(n-}}\end{array}$ & $\begin{array}{l}\text { This g-prior is based on the Global } \\
\text { Empirical Bayes approach. } \\
\text { There is not closed-form solution for } \\
\text { this g-prior since the marginal } \\
\text { likelihood is not tractable. However, } \\
\text { as suggested by George and Foster } \\
\text { (2000), numerical optimization can be } \\
\text { used as a solution. } \\
\text { Liang et al. (2008) recommend an EM } \\
\text { algorithm that provides a maximum } \\
\text { likelihood estimation for g: } \\
g^{(i+1)} \\
=\text { max }\left\{\sum_{\gamma} p^{(i)}\left(M_{\gamma} \mid r\right) x \frac{\left.R_{\gamma}^{2} / \Sigma_{\gamma}, p^{(i)}\left(M_{\gamma /} \mid \gamma\right) p_{\gamma /}\right)}{\left(1-\left(g^{(i)} /\left(1+g^{(i)}\right)\right) R_{\gamma}^{2}\right) /(n-}\right. \\
-1,0\} \\
\text { Under this algorithm, Empirical Bayes } \\
\text { posterior model probabilities can be } \\
\text { attained at convergence. } \\
\text { This g-prior resolves the information } \\
\text { paradox and is asymptotic consistent } \\
\text { for prediction. However, it is not } \\
\text { consistent for model selection. }\end{array}$ & $\begin{array}{l}\text { A common g-prior is } \\
\text { evaluated for all models. } \\
\text { The estimate for g } \\
\text { coincides with the } \\
\text { maximum marginal } \\
\text { likelihood of the data, } \\
\text { averaged over all models. }\end{array}$ \\
\hline
\end{tabular}


DIMISKI Student Performance in Science

\begin{tabular}{|c|c|c|}
\hline $\begin{array}{l}\text { 20) } \\
\pi_{a, b}(c) \\
=M(1+c)^{-(1+a)} \exp \left\{-\frac{b}{1+c}\right\} \\
\text { where } \\
M=b^{a}\left(\int_{0}^{b} t^{a-1} e^{-t} d t\right)^{-1} \\
\text { and } \\
\quad \pi_{a}(c) \\
=a(1+c)^{-(1+a)} \text { for } c \in(0, \infty)\end{array}$ & $\begin{array}{l}\text { This g-prior is based on Fully Bayes } \\
\text { approaches. } \\
\text { The variance is known. } \\
\text { To implement this approach, } \\
\text { hyperpriors for two hyperparameters c } \\
\text { and w should be defined. } \\
\text { c is a hyperparameter for the average } \\
\text { size of the regression coefficients } \\
\text { matrix for model } \gamma\left(\beta_{\gamma}\right) \text {. } \\
\text { w is a hyperparameter for the average } \\
\text { number of nonzero coefficients in the } \\
\text { model } \gamma \text {. } \\
\text { The term }(1+c) \text { for c } \epsilon(0, \infty) \text { follows an } \\
\text { incomplete Gamma distribution }(a, b) \text {, } \\
\text { where a and b are hyperparameters, } \\
\text { with default choices at } b=0 \text { and } a=1 \text {. }\end{array}$ & $\begin{array}{l}\text { It is suggested by Cui and } \\
\text { George (2007). }\end{array}$ \\
\hline $\begin{array}{l}21) \\
g(x, \lambda) \\
=K_{2} \lambda^{\frac{1}{2} p-a} \exp \left(-\frac{1}{2} \lambda|| \chi||^{2}\right), \\
0<\lambda \leq 1,|\chi|^{2}>0 \\
\text { where } \mathrm{p} \geq 6 \text { and } 0 \leq \mathrm{a}<1 \\
\text { and if } \mathrm{p}=5 \text { then } 1 / 2 \leq \mathrm{a}<1\end{array}$ & $\begin{array}{l}\text { These family of priors are used to } \\
\text { provide proper Bayes minimax } \\
\text { estimators when the mean of a } \\
\text { multivariate normal distribution is } \\
\text { estimated (under identity covariance } \\
\text { matrix and a loss in squared errors). } \\
\text { The unconditional density for } \lambda \text { with } \\
\text { respect to Lebesgue measure is given } \\
\text { by } \lambda^{-a} /(1-a) \text { for any } a, 0 \leq \mathrm{a}<1\end{array}$ & $\begin{array}{l}\text { It is introduced by } \\
\text { Strawderman (1971). }\end{array}$ \\
\hline \multicolumn{3}{|c|}{ Hyper -g priors (Ley and Steel (2012)) } \\
\hline $\begin{aligned} p(g)=\frac{\Gamma(b+c)}{\Gamma(b) \Gamma(c)} g^{b-1}(1 \\
+g)^{-(b+c)}\end{aligned}$ & $\begin{array}{l}\text { The shrinkage factor } \delta=g /(1+\mathrm{g}) \\
\text { follows a Beta prior distribution } \\
\text { Beta(b,c), leading the prior on } \mathrm{g} \text { to } \\
\text { follow a Gamma-Gamma distribution } \\
\text { (Bernardo and Smith }(1994), \mathrm{p} .120) \\
\text { or, alternatively, an inverted Beta } \\
\text { distribution (Zellner (1971), p.375): } \\
p(g)=\frac{\Gamma(b+c)}{\Gamma(b) \Gamma(c)} g^{b-1}(1+g)^{-(b+c)} \\
\text { which has the following properties: } \\
\qquad E[g]=\frac{b}{c-1}, \text { provided that } c>1 \\
\text { and } \\
\operatorname{Var}[g] \\
=\frac{b(b+c-1)}{(c-1)^{2}(c-2)} \text {, provided that } c>2\end{array}$ & $\begin{array}{l}\text { It is suggested by Ley and } \\
\text { Steel }(2012) \text {. Following } \\
\text { Fenandez et al. (2001b), } \\
\text { they set } \mathrm{b} / \mathrm{c}=\max \left\{\mathrm{n}, \mathrm{k}^{2}\right\} \\
\text { and they get a Benchmark } \\
\text { Beta prior with a fixed } \\
\text { value for } \mathrm{b}=1 \text { and } \mathrm{c}=1 / \\
\text { max }\left\{\mathrm{n}, \mathrm{k}^{2}\right\} \text {. This leads to } \\
\text { a single hyper-g prior with } \\
\alpha=2^{*} \max \left\{\mathrm{n}^{2} \mathrm{k}^{2}\right\}+1 / \\
\max \left\{\mathrm{n}, \mathrm{k}^{2}\right\}=2 \quad+ \\
\max \left\{\mathrm{n}, \mathrm{k}^{2}\right\} \\
\text { In that case, Beta } \\
\text { distribution becomes } \\
\text { Beta }(\mathrm{b}, \mathrm{c})= \\
\text { Beta }\left(1,1 / \max \left\{\mathrm{n}, \mathrm{k}^{2}\right\}\right)= \\
\text { Beta }(1,(\alpha-2) / 2) \\
\text { It is known as the "hg- } \\
\text { BRIC" prior. }\end{array}$ \\
\hline
\end{tabular}


Review of Economic Analysis 13 (2021) 157-212

\begin{tabular}{|c|c|c|}
\hline & $\begin{array}{l}\text { This prior on } g \text { leads to the following } \\
\text { prior on the regression coefficients: } \\
p\left(\beta_{k} \mid M_{k}, \sigma\right)=\frac{\Gamma(b+c) \Gamma\left(c+\frac{k_{j}}{2}\right)\left|Z_{k}^{\prime} Z_{k}\right|^{1 / 2}}{\Gamma(b) \Gamma(c)(2 \pi)^{k_{j}} / 2 \sigma^{k_{j}}} \\
\mathrm{x} \\
\Psi\left(\mathrm{c}+\frac{k_{j}}{2}, \frac{k_{j}}{2}-b+1 ; \frac{\beta_{k}^{\prime} Z_{j}^{\prime} z_{j} \beta_{j}}{2 \sigma^{2}}\right)\end{array}$ & \\
\hline $\begin{array}{l}\text { 23) } \\
E\left[\frac{g}{1+g}\right]=\frac{N}{1+N} " h g-U I P^{\prime \prime} \\
\text { and } \\
\begin{array}{r}E\left[\frac{g}{1+g}\right]=\frac{K^{2}}{1+K^{2}} " h g \\
\quad-R I C^{\prime \prime}\end{array}\end{array}$ & $\begin{array}{l}\text { The shrinkage factor } \delta=g /(1+g) \\
\text { follows a beta distribution Beta }(1 \text {, } \\
(\alpha / 2)-1) \\
\text { The hyperparameter } \alpha \text { expresses the } \\
\text { prior beliefs on the shrinkage factor } \delta \text {. }\end{array}$ & $\begin{array}{l}\text { Building on the grounds of } \\
\text { Liang et al. (2008), } \\
\text { Feldkircher and Zeugner } \\
\text { (2009), specify the } \\
\text { hyperparameter } \alpha \text { as } \\
\text { follows: } \\
\alpha=2+2 / \mathrm{n} \text { and } \alpha=2+ \\
2 / \mathrm{k}^{2} \\
\text { The first one is known as } \\
\text { "hg-UIP" and the second } \\
\text { one as "hg-RIC". }\end{array}$ \\
\hline $\begin{array}{l}\text { 24) } \\
p\left(k_{i}\right) \propto k_{i}^{-1 / 2}\left(1-k_{i}\right)^{-1 / 2} \\
p\left(\lambda_{i}\right) \propto\left(1+\lambda_{i}^{2}\right)^{-1} \\
\text { under the specification that } \mathrm{b}=\mathrm{c}=1 / 2\end{array}$ & $\begin{array}{l}\text { If the random shrinkage coefficient } \mathrm{k}_{\mathrm{i}} \\
\text { follows a Beta distribution Beta }(\mathrm{b}, \mathrm{c}) \\
\text { then, the prior for the local shrinkage } \\
\text { parameter } \lambda_{\mathrm{i}} \text { is: } \\
p\left(\lambda_{i}\right) \propto \lambda_{i}^{2 c-1}\left(1+\lambda_{i}^{2}\right)^{-(b+c)}\end{array}$ & $\begin{array}{l}\text { It is introduced by } \\
\text { Carvalho (2010) and is } \\
\text { known as the "Horseshoe" } \\
\text { prior. } \\
\text { He specifies the values for } \\
\mathrm{b}, \mathrm{c}=1 / 2 \text { such that the } \\
\text { random shrinkage factor } \mathrm{ki} \\
\sim \text { Beta }(1 / 2,1 / 2)\end{array}$ \\
\hline $\begin{array}{l}\text { 25) } \\
p(g) \\
=\frac{g^{b}(1+g)^{-a-z-1}}{B(a+1, z+1)} I_{(0, \infty)}(g) \\
\text { with } \alpha>-1, z>-1\end{array}$ & $\begin{array}{l}\text { The term } 1 /(1+\mathrm{g}) \text { follows a Beta } \\
\text { distribution } \operatorname{Be}(\alpha+1, \mathrm{z}+1) \text {. } \\
\text { Defining new terms such that } \alpha+1=\mathrm{b} \\
\text { and } \mathrm{z}+1=\mathrm{c} \text {, the term } 1 /(1+\mathrm{g}) \text { follows a } \\
\text { Beta distribution Beta }(\mathrm{b}, \mathrm{c})=\text { Beta }(1 / 4 \text {, } \\
(\mathrm{n}-\mathrm{q}-1) / 2-\mathrm{b}) \\
\text { where } \\
\mathrm{b}=\alpha+1=-3 / 4+1=1 / 4\end{array}$ & $\begin{array}{l}\text { It is proposed by } \\
\text { Maruyama and George } \\
(2011) \text { in the context of } \\
\text { formulating selection } \\
\text { criteria based on a fully } \\
\text { Bayes formulation. For } \\
\mathrm{q}<\mathrm{n}-1 \text {, they constrain the } \\
\text { choice for } \alpha \text { to the interval } \\
(-1,-1 / 2) \text {. The default } \\
\text { choices for these two }\end{array}$ \\
\hline
\end{tabular}




\section{DIMISKI Student Performance in Science}

\begin{tabular}{|c|c|c|}
\hline & $\begin{array}{l}\mathrm{c}=\mathrm{z}+1=(\mathrm{n}-5) / 2-\mathrm{q} / 2-\alpha+1= \\
(\mathrm{n}-\mathrm{q}-1) / 2-4 / 2-\alpha+1= \\
(\mathrm{n}-\mathrm{q}-1) / 2-1-\alpha= \\
(\mathrm{n}-\mathrm{q}-1) / 2-(\alpha+1)= \\
(\mathrm{n}-\mathrm{q}-1) / 2-\mathrm{b} \\
\text { and } \\
-1<\alpha<-1 / 2 \rightarrow 0<\alpha+1<1 / 2 \rightarrow \\
0<\mathrm{b}<1 / 2 \\
\mathrm{z}>-1 \rightarrow \mathrm{z}+1>0 \rightarrow \mathrm{c}>0\end{array}$ & $\begin{array}{l}\text { hyperparameters are: } \alpha=- \\
3 / 4 \text { and } z=(n-5) / 2-q / 2- \\
\alpha .\end{array}$ \\
\hline $\begin{array}{l}\text { 26) } \\
\begin{array}{r}p(g)=\frac{\Gamma(b+c)}{\Gamma(b) \Gamma(c)} g^{b-1}(1 \\
+g)^{-(b+c)}\end{array}\end{array}$ & $\begin{array}{l}\text { The shrinkage factor follows } a b=\text { Beta } \\
\text { distribution } \delta \sim B e(b, c) \text {. } \\
\text { The term } b=0 \text { and by setting } a=2 \text {, the } \\
\text { term } c=a / 2-1=0 \text {. }\end{array}$ & $\begin{array}{l}\text { Following Ley and Steel } \\
(2012), \text { Bottolo and } \\
\text { Richardson (2008) adopt a } \\
\text { hyper-g prior with a=2, } \\
\text { but make it proper by } \\
\text { truncating the right tail at } \\
\max \left\{\mathrm{n}^{2}\right\} \text {. }\end{array}$ \\
\hline $\begin{array}{l}\text { 27) } \\
\begin{aligned} p(g)=\frac{\Gamma(b+c)}{\Gamma(b) \Gamma(c)} g^{b-1}(1 \\
+g)^{-(b+c)}\end{aligned}\end{array}$ & $\begin{array}{l}\text { They recommend the use of } \mathrm{b}=1 \text { and } \\
\mathrm{c}=1 / 2 \text {, while truncating } \mathrm{g} \text { to be } \\
g>\frac{(n+1)}{k_{j}+3}-1\end{array}$ & 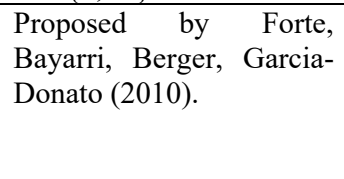 \\
\hline
\end{tabular}


Review of Economic Analysis 13 (2021) 157-212

Table 2: List of countries

\begin{tabular}{|c|c|}
\hline Australia & Algeria \\
\hline Austria & Brazil \\
\hline Belgium & B-S-J-G (China) \\
\hline Canada & Bulgaria \\
\hline Chile & CABA (Argentina) \\
\hline Czech Republic & Colombia \\
\hline Denmark & Costa Rica \\
\hline Estonia & Croatia \\
\hline Finland & Cyprus \\
\hline France & Dominican Republic \\
\hline Germany & FYROM \\
\hline Greece & Georgia \\
\hline Hungary & Hong Kong (China) \\
\hline Iceland & Indonesia \\
\hline Ireland & Jordan \\
\hline Israel & Kosovo \\
\hline Italy & Lebanon \\
\hline Japan & Lithuania \\
\hline Korea & Macao (China) \\
\hline Latvia & Malta \\
\hline Luxembourg & Moldova \\
\hline Mexico & Montenegro \\
\hline Netherlands & Peru \\
\hline New Zealand & Qatar \\
\hline Norway & Romania \\
\hline Poland & Russia \\
\hline Portugal & Singapore \\
\hline Slovak Republic & Chinese Taipei \\
\hline Slovenia & Thailand \\
\hline Spain & Trinidad and Tobago \\
\hline Sweden & Tunisia \\
\hline Switzerland & United Arab Emirates \\
\hline Turkey & Uruguay \\
\hline United Kingdom & Viet Nam \\
\hline United States & Kazakhstan \\
\hline Albania & Malaysia \\
\hline
\end{tabular}

Source: This list of countries is taken from PISA 2015

dataset. More information can be found at http://www.oecd.org/pisa/data/ 
DIMISKI Student Performance in Science

Table 3: Summary statistics for the dependent and the independent variables

\begin{tabular}{|c|c|c|c|c|c|}
\hline & Observations & Mean & Std.Dev & Min & Max \\
\hline \multicolumn{6}{|l|}{ Dependent Variable } \\
\hline Students' performance in science & 72 & 465.297 & 49.125 & 331.639 & 555.575 \\
\hline \multicolumn{6}{|l|}{ Independent Variables } \\
\hline \multicolumn{6}{|l|}{ Educational Outcomes } \\
\hline Repetition of a grade & 72 & 0 & 1 & -1.031 & 4.055 \\
\hline Non-attendance in pre-primary education & 56 & 0 & 1 & -0.699 & 5.011 \\
\hline Attendance in pre-primary education 1 & 56 & 0 & 1.755 & -3.043 & 3.569 \\
\hline Attendance in pre-primary education 2 & 56 & 0 & 1.151 & -1.897 & 3.229 \\
\hline Numbers of years in pre-primary education & 56 & 0 & 1 & -2.71 & 2.036 \\
\hline \multicolumn{6}{|l|}{ Participation in Education } \\
\hline Attendance in schools 1 & 71 & 0 & 1.435 & -5.117 & 1.941 \\
\hline Attendance in schools 2 & 71 & 0 & 1.026 & -3.554 & 2.915 \\
\hline \multicolumn{6}{|l|}{ Fields of Education } \\
\hline $\begin{array}{l}\text { Expectations to work in science-related } \\
\text { fields 1a }\end{array}$ & 72 & 0 & 2.274 & -3.435 & 5.593 \\
\hline $\begin{array}{l}\text { Expectations to work in science-related } \\
\text { fields } 2 a\end{array}$ & 72 & 0 & 1.557 & -2.756 & 8.19 \\
\hline $\begin{array}{l}\text { Expectations to work in science-related } \\
\text { fields } 3 \mathrm{a}\end{array}$ & 72 & 0 & 1.489 & -2.96 & 5.234 \\
\hline $\begin{array}{l}\text { Expectations to work in science-related } \\
\text { fields } 4 \mathrm{a}\end{array}$ & 72 & 0 & 0.962 & -2.764 & 1.92 \\
\hline Relative risk/Increased likelihood $1 \mathrm{~b}$ & 70 & 0 & 1.146 & -4.483 & 2.608 \\
\hline Relative risk/Increased likelihood $2 \mathrm{~b}$ & 70 & 0 & 1.049 & -4.778 & 3.885 \\
\hline Relative risk/Increased likelihood 3b & 70 & 0 & 0.963 & -2.764 & 2.593 \\
\hline \multicolumn{6}{|l|}{ Student evaluation and assessment } \\
\hline Students' evaluation and assessment 1 & 67 & 0 & 1.385 & -3.492 & 2.87 \\
\hline Students' evaluation and assessment 2 & 67 & 0 & 1.374 & -2.793 & 3.867 \\
\hline Students' evaluation and assessment 3 & 67 & 0 & 1.184 & -2.486 & 2.811 \\
\hline Students' evaluation and assessment 4 & 67 & 0 & 0.980 & -2.682 & 2.217 \\
\hline \multicolumn{6}{|l|}{ Classroom environment/School climate } \\
\hline School characteristics 1a & 72 & 0 & 1.351 & -2.115 & 3.800 \\
\hline School characteristics $2 \mathrm{a}$ & 72 & 0 & 0.849 & -2.690 & 2.730 \\
\hline Average time spent in learning $1 \mathrm{~b}$ & 57 & 0 & 1.576 & -2.687 & 6.277 \\
\hline Average time spent in learning $2 b$ & 57 & 0 & 0.883 & -1.865 & 2.190 \\
\hline \multicolumn{6}{|l|}{ Students' engagement, drive and beliefs } \\
\hline Benefits from science knowledge 1a & 57 & 0 & 1.698 & -4.127 & 3.66 \\
\hline Benefits from science knowledge $2 \mathrm{a}$ & 57 & 0 & 1.039 & -2.613 & 3.044 \\
\hline $\begin{array}{l}\text { Gender difference (boys-girls) in benefits } \\
\text { from science knowledge } 1 \mathrm{~b}\end{array}$ & 57 & 0 & 1.623 & -2.882 & 3.751 \\
\hline Skip/arrive late in class & 57 & 0 & 1.795 & -4.298 & 4.092 \\
\hline Skip/arrive late in class & 57 & 0 & 1.225 & -2.282 & 2.876 \\
\hline
\end{tabular}


Review of Economic Analysis 13 (2021) 157-212

\begin{tabular}{|c|c|c|c|c|c|}
\hline \multirow[t]{2}{*}{ After-School activities } & \multirow[b]{2}{*}{ Observations } & \multirow[b]{2}{*}{ Mean } & \multirow[b]{2}{*}{ Std.Dev } & \multirow[b]{2}{*}{ Min } & \multirow[b]{2}{*}{ Max } \\
\hline & & & & & \\
\hline $\begin{array}{l}\text { Average time spent in studying after } \\
\text { school } 1\end{array}$ & 57 & 0 & 1.893 & -3.586 & 5.394 \\
\hline \multicolumn{6}{|l|}{ Access to ICT } \\
\hline Access to ICT & 72 & 0 & 1 & -1.623 & 2.758 \\
\hline \multicolumn{6}{|l|}{ Performance and socio-economic status } \\
\hline Difference in science performance 1c & 61 & 0 & 1.549 & -3.004 & 2.768 \\
\hline Difference in science performance 2c & 61 & 0 & 1.269 & -2.716 & 2.996 \\
\hline Difference in science performance $3 \mathrm{c}$ & 61 & 0 & 1.074 & -2.606 & 2.452 \\
\hline \multicolumn{6}{|l|}{ Performance and diversity } \\
\hline Students with an immigrant background 1a & 66 & 0 & 1.354 & -3.634 & 3.145 \\
\hline $\begin{array}{l}\text { Difference in science performance } \\
\text { between immigrant and non-immigrant } \\
\text { students } 1 \mathrm{~b}\end{array}$ & 66 & 0 & 1.263 & -4.093 & 3.193 \\
\hline \multicolumn{6}{|l|}{ Resources for education } \\
\hline Resources for science course 1a & 68 & 0 & 1.379 & -2.839 & 2.321 \\
\hline Resources for science course $2 \mathrm{a}$ & 68 & 0 & 1.009 & -3.623 & 1.617 \\
\hline Shortage in resources $1 \mathrm{~b}$ & 72 & 0 & 1.415 & -3.370 & 2.647 \\
\hline Shortage in resources $2 b$ & 72 & 0 & 1.301 & -3.084 & 3.765 \\
\hline \multicolumn{6}{|l|}{ Professional Development of Teachers } \\
\hline Professional Development of Teachers & 72 & 0 & 1 & -1.906 & 2.122 \\
\hline \multicolumn{6}{|l|}{ School evaluation } \\
\hline Students' evaluation 1a & 72 & 0 & 1.497 & -3.421 & 3.540 \\
\hline Students' evaluation $2 \mathrm{a}$ & 72 & 0 & 1.102 & -1.922 & 3.442 \\
\hline \multicolumn{6}{|l|}{ Governance } \\
\hline School autonomy & 72 & 0 & 1 & -2.366 & 1.898 \\
\hline $\begin{array}{l}\text { Area of residence as a criterion for } \\
\text { admission }\end{array}$ & 72 & 0 & 1 & -1.664 & 1.995 \\
\hline
\end{tabular}

Note: The independent variables refer to the new variables that are constructed using the Principal Component Analysis. 
DIMISKI Student Performance in Science

Table 4: Description of the New set of independent variables

\begin{tabular}{|c|c|c|c|}
\hline Variables & Notation & Number of PC & Description \\
\hline \multicolumn{4}{|l|}{ 1) Educational Outcomes } \\
\hline Repetition of a grade & EducOut1 & None & $\begin{array}{l}\text { \% of students who } \\
\text { had repeated a grade } \\
\text { in primary, lower } \\
\text { secondary or upper } \\
\text { secondary education }\end{array}$ \\
\hline $\begin{array}{l}\text { Non-attendance in pre-primary } \\
\text { education }\end{array}$ & EducOut2 & None & $\begin{array}{l}\% \text { of students who } \\
\text { had not attend pre- } \\
\text { primary education }\end{array}$ \\
\hline Attendance in pre-primary education & PC11, PC21 & $\begin{array}{l}\text { PC11 is the first } \\
\text { principal component } \\
\text { (that explains most of } \\
\text { the variation) and } \\
\text { PC2 } 1 \text { is the second in } \\
\text { row principal } \\
\text { component. }\end{array}$ & $\begin{array}{l}\% \text { of students who } \\
\text { attend pre-primary } \\
\text { education. }\end{array}$ \\
\hline $\begin{array}{l}\text { Number of years in pre-primary } \\
\text { education }\end{array}$ & EducOut9 & None & $\begin{array}{l}\text { Number of years that } \\
\text { students spend for } \\
\text { pre-primary education }\end{array}$ \\
\hline \multicolumn{4}{|l|}{ 2)Participation in Education } \\
\hline Attendance in schools & $\mathrm{PC} 12, \mathrm{PC} 22$ & $\begin{array}{l}\text { PC11 is the first } \\
\text { principal component } \\
\text { (that explains most of } \\
\text { the variation) and } \\
\text { PC } 21 \text { is the second in } \\
\text { row principal } \\
\text { component. }\end{array}$ & $\begin{array}{l}\% \text { of students who } \\
\text { attend different kind } \\
\text { of schools (e.g } \\
\text { private, public, } \\
\text { government } \\
\text { dependent) }\end{array}$ \\
\hline \multicolumn{4}{|l|}{ 3) Fields of Education } \\
\hline $\begin{array}{l}\text { Expectations to work in science- } \\
\text { related fields (a) }\end{array}$ & $\begin{array}{l}\text { PC13a, } \\
\text { PC23a, } \\
\text { PC33a, PC43a }\end{array}$ & $\begin{array}{l}\text { PC13a is the first } \\
\text { principal component } \\
\text { (that explains most of } \\
\text { the variation) and } \\
\text { PC23a is the second } \\
\text { in row principal } \\
\text { component, PC } 33 \mathrm{a} \text { is } \\
\text { the third and PC43a is } \\
\text { the fourth. }\end{array}$ & $\begin{array}{l}\% \text { of students who } \\
\text { expect to work in } \\
\text { science-related } \\
\text { professional and } \\
\text { technical occupations } \\
\text { at the age } 30 \text {. }\end{array}$ \\
\hline Relative risk/increased likelihood (b) & $\begin{array}{l}\text { PC13b, } \\
\text { PC } 23 b, \\
\text { PC } 33 b\end{array}$ & $\begin{array}{l}\text { PC13b is the first } \\
\text { principal component } \\
\text { (that explains most of } \\
\text { the variation) and } \\
\text { PC } 23 \mathrm{~b} \text { is the second } \\
\text { in row principal } \\
\text { component, PC } 33 \mathrm{~b} \text { is } \\
\text { the third. }\end{array}$ & $\begin{array}{l}\text { The relative risk of } \\
\text { boys expecting to } \\
\text { work in science- } \\
\text { related professional } \\
\text { and technical } \\
\text { occupations at age } 30 \\
\text { (expressed in points). }\end{array}$ \\
\hline
\end{tabular}


Review of Economic Analysis 13 (2021) 157-212

\begin{tabular}{|c|c|c|c|}
\hline Variables & Notation & Number of PC & Description \\
\hline \multicolumn{4}{|l|}{$\begin{array}{l}\text { 4) Student evaluation and } \\
\text { assessment }\end{array}$} \\
\hline Students' evaluation and assessment & $\begin{array}{l}\mathrm{PC} 14, \mathrm{PC} 24, \\
\mathrm{PC} 34, \mathrm{PC} 44\end{array}$ & $\begin{array}{l}\text { PC14 is the first } \\
\text { principal component } \\
\text { (that explains most of } \\
\text { the variation) and } \\
\text { PC } 24 \text { is the second in } \\
\text { row principal } \\
\text { component, PC } 34 \text { is } \\
\text { the third and PC } 44 \text { is } \\
\text { the fourth. }\end{array}$ & $\begin{array}{l}\text { The number of } \\
\text { students who are } \\
\text { evaluated and } \\
\text { assessed in alternative } \\
\text { ways (e.g. mandatory } \\
\text { or no- mandatory } \\
\text { tests, teacher- } \\
\text { developed tests etc.) }\end{array}$ \\
\hline \multicolumn{4}{|l|}{$\begin{array}{l}\text { 5) Classroom environment/school } \\
\text { climate }\end{array}$} \\
\hline School characteristics (a) & PC15a, PC25a & $\begin{array}{l}\text { PC15a is the first } \\
\text { principal component } \\
\text { (that explains most of } \\
\text { the variation) and } \\
\text { PC25a is the second } \\
\text { in row principal } \\
\text { component. }\end{array}$ & $\begin{array}{l}\text { Mean ratio defined } \\
\text { between students and } \\
\text { classroom } \\
\text { characteristics. }\end{array}$ \\
\hline Average time spent in learning (b) & $\begin{array}{l}\text { PC15b, } \\
\text { PC25b }\end{array}$ & $\begin{array}{l}\text { PC15b is the first } \\
\text { principal component } \\
\text { (that explains most of } \\
\text { the variation) and } \\
\text { PC } 25 \mathrm{~b} \text { is the second } \\
\text { in row principal } \\
\text { component. }\end{array}$ & $\begin{array}{l}\text { The average time } \\
\text { spent after school in } \\
\text { studying science and } \\
\text { non-science lessons } \\
\text { (expressed in hours). }\end{array}$ \\
\hline \multicolumn{4}{|l|}{$\begin{array}{l}\text { 6) Students' engagement, drive and } \\
\text { beliefs }\end{array}$} \\
\hline Benefits from science knowledge (a) & PC16a, PC26a & $\begin{array}{l}\text { PC26a is the first } \\
\text { principal component } \\
\text { (that explains most of } \\
\text { the variation) and } \\
\text { PC26a is the second } \\
\text { in row principal } \\
\text { component. }\end{array}$ & $\begin{array}{l}\text { Mean index of } \\
\text { students who report } \\
\text { that learning about } \\
\text { science is beneficial } \\
\text { in different ways. }\end{array}$ \\
\hline $\begin{array}{l}\text { Gender difference (boys-girls) in } \\
\text { benefits from science knowledge (b) }\end{array}$ & $\mathrm{PC} 16 \mathrm{~b}$ & $\begin{array}{l}\text { PC16b is the first } \\
\text { principal component } \\
\text { (that explains most of } \\
\text { the variation). }\end{array}$ & $\begin{array}{l}\text { Mean index of the } \\
\text { gender difference } \\
\text { (boys-girls) who } \\
\text { report that learning } \\
\text { about science is } \\
\text { beneficial in different } \\
\text { ways. }\end{array}$ \\
\hline Skip/arrive late in class (c) & $\mathrm{PC} 16 \mathrm{c}, \mathrm{PC} 26 \mathrm{c}$ & $\begin{array}{l}\text { PC16c is the first } \\
\text { principal component } \\
\text { (that explains most of } \\
\text { the variation) and } \\
\text { PC } 26 \mathrm{c} \text { is the second } \\
\text { in row principal } \\
\text { component. }\end{array}$ & $\begin{array}{l}\text { The number of } \\
\text { students who refer } \\
\text { skipping/arriving late } \\
\text { at classes two weeks } \\
\text { prior to the test. }\end{array}$ \\
\hline
\end{tabular}


DIMISKI Student Performance in Science

\begin{tabular}{|c|c|c|c|}
\hline Variables & Notation & Number of PC & Description \\
\hline \multicolumn{4}{|l|}{ 7) After-School activities } \\
\hline $\begin{array}{l}\text { Average time spent in studying after } \\
\text { school }\end{array}$ & PC17 & $\begin{array}{l}\text { PC17 is the first } \\
\text { principal component } \\
\text { (that explains most of } \\
\text { the variation). }\end{array}$ & $\begin{array}{l}\text { The average time per } \\
\text { week spent after } \\
\text { school in studying } \\
\text { science and non- } \\
\text { science lessons } \\
\text { (expressed in hours). }\end{array}$ \\
\hline \multicolumn{4}{|l|}{ 8) Access to ICT } \\
\hline Access to ICT & ICT & None & $\begin{array}{l}\text { Number of computers } \\
\text { per student. }\end{array}$ \\
\hline \multicolumn{4}{|l|}{$\begin{array}{l}\text { 9) Performance and socio-economic } \\
\text { status }\end{array}$} \\
\hline Difference in science performance (c) & $\begin{array}{l}\text { PC19c, } \\
\text { PC29c, PC39c }\end{array}$ & $\begin{array}{l}\text { PC13b is the first } \\
\text { principal component } \\
\text { (that explains most of } \\
\text { the variation) and } \\
\text { PC23b is the second } \\
\text { in row principal } \\
\text { component, PC } 33 \mathrm{~b} \text { is } \\
\text { the third. }\end{array}$ & $\begin{array}{l}\text { Difference in science } \\
\text { performance } \\
\text { associated with } \\
\text { different reasons. } \\
\text { (expressed in score } \\
\text { points). }\end{array}$ \\
\hline \multicolumn{4}{|l|}{ 10) Performance and Diversity } \\
\hline $\begin{array}{l}\text { Students with an immigrant } \\
\text { background (a) }\end{array}$ & PC110a & $\begin{array}{l}\text { PC110a is the first } \\
\text { principal component } \\
\text { (that explains most of } \\
\text { the variation) }\end{array}$ & $\begin{array}{l}\% \text { of students with or } \\
\text { without an immigrant } \\
\text { background. }\end{array}$ \\
\hline $\begin{array}{l}\text { Difference in science performance } \\
\text { between immigrant and non- } \\
\text { immigrant students (b) }\end{array}$ & $\mathrm{PC} 110 \mathrm{~b}$ & $\begin{array}{l}\text { PC110b is the first } \\
\text { principal component } \\
\text { (that explains most of } \\
\text { the variation). }\end{array}$ & $\begin{array}{l}\text { Difference is science } \\
\text { performance between } \\
\text { immigrant and non- } \\
\text { immigrant students } \\
\text { (expressed in score- } \\
\text { points). }\end{array}$ \\
\hline \multicolumn{4}{|l|}{ 11) Resources for education } \\
\hline Resources for science course (a) & $\begin{array}{l}\text { PC111a, } \\
\text { PC211a }\end{array}$ & $\begin{array}{l}\text { PC13b is the first } \\
\text { principal component } \\
\text { (that explains most of } \\
\text { the variation) and } \\
\text { PC23b is the second } \\
\text { in row principal } \\
\text { component. }\end{array}$ & $\begin{array}{l}\% \text { of science teachers } \\
\text { who are qualified to } \\
\text { teach science. }\end{array}$ \\
\hline Shortage in resources (b) & $\begin{array}{l}\text { PC111b, } \\
\text { PC211b }\end{array}$ & $\begin{array}{l}\text { PC13b is the first } \\
\text { principal component } \\
\text { (that explains most of } \\
\text { the variation) and } \\
\text { PC } 23 \mathrm{~b} \text { is the second } \\
\text { in row principal } \\
\text { component. }\end{array}$ & $\begin{array}{l}\text { Mean index of } \\
\text { shortage in } \\
\text { educational material. }\end{array}$ \\
\hline
\end{tabular}


Review of Economic Analysis 13 (2021) 157-212

\begin{tabular}{|c|c|c|c|}
\hline \multicolumn{4}{|l|}{$\begin{array}{l}\text { 12) Professional Development of } \\
\text { teachers }\end{array}$} \\
\hline Variables & Notation & Number of PC & Description \\
\hline $\begin{array}{l}\text { Professional Development of } \\
\text { Teachers }\end{array}$ & ProfDevTeach & None & $\begin{array}{l}\% \text { of teachers } \\
\text { attended a programme } \\
\text { of professional } \\
\text { development in the } \\
\text { previous three } \\
\text { months. }\end{array}$ \\
\hline \multicolumn{4}{|l|}{ 13) School evaluation } \\
\hline School evaluation & $\begin{array}{l}\text { PC113, } \\
\text { PC213 }\end{array}$ & $\begin{array}{l}\text { PC113 is the first } \\
\text { principal component } \\
\text { (that explains most of } \\
\text { the variation) and } \\
\text { PC } 213 \text { is the second } \\
\text { in row principal } \\
\text { component. }\end{array}$ & $\begin{array}{l}\% \text { of students who use } \\
\text { internal/external } \\
\text { evaluation. }\end{array}$ \\
\hline \multicolumn{4}{|l|}{ 14) Governance } \\
\hline School autonomy (a) & Governance1 & None & $\begin{array}{l}\text { Mean index of school } \\
\text { autonomy (\% of tasks } \\
\text { for which the schools } \\
\text { have considerable } \\
\text { responsibility) }\end{array}$ \\
\hline $\begin{array}{l}\text { Area of residence as a criterion of } \\
\text { admission }\end{array}$ & Governance2 & None & $\begin{array}{l}\% \text { of students in } \\
\text { schools where } \\
\text { residence in a } \\
\text { particular area is } \\
\text { always considered for } \\
\text { admission to school }\end{array}$ \\
\hline
\end{tabular}


DIMISKI Student Performance in Science

Table 5: Gini and OLS results using BMA methodology when the dependent variable is students' performance in Science

\begin{tabular}{|c|c|c|c|c|c|c|}
\hline & \multicolumn{3}{|c|}{ Gini-BMA } & \multicolumn{3}{|c|}{ OLS-BMA } \\
\hline & PIP & PSE & PSD & PIP & PSE & PSD \\
\hline PC110b & 0.9389 & -19.092 & 9.224 & 0.4483 & 3.878 & 6.463 \\
\hline PC25a & 0.9281 & 17.136 & 7.469 & 0.3110 & -0.489 & 5.543 \\
\hline PC11 & 0.8167 & -8.691 & 6.976 & 0.3103 & 0.053 & 7.079 \\
\hline PC23a & 0.7882 & -11.631 & 8.265 & 0.2801 & -0.672 & 3.111 \\
\hline PC33b & 0.7711 & 18.040 & 13.241 & 0.2663 & 0.207 & 3.818 \\
\hline EducOut2 & 0.7301 & -10.446 & 8.504 & 0.8377 & -8.755 & 6.666 \\
\hline PC17 & 0.6860 & -5.880 & 5.476 & 0.3075 & 0.101 & 4.104 \\
\hline PC44 & 0.6818 & 5.905 & 5.530 & 0.4749 & -4.665 & 6.856 \\
\hline PC110a & 0.6486 & 7.391 & 7.508 & 0.9267 & -16.699 & 8.515 \\
\hline PC111a & 0.6122 & 7.398 & 8.006 & 0.3201 & 1.369 & 3.989 \\
\hline PC25b & 0.6069 & 4.667 & 5.564 & 0.3732 & 2.502 & 5.526 \\
\hline PC34 & 0.5621 & -4.735 & 6.151 & 0.5649 & 3.872 & 4.735 \\
\hline EducOut1 & 0.5381 & 4.396 & 5.587 & 0.7492 & -10.257 & 8.065 \\
\hline PC24 & 0.4771 & -3.226 & 5.278 & 0.414 & -2.453 & 5.287 \\
\hline Governance1 & 0.4764 & 3.462 & 5.806 & 0.4891 & -3.121 & 10.056 \\
\hline PC13a & 0.4686 & 4.233 & 6.451 & 0.8904 & -14.292 & 7.359 \\
\hline Governance2 & 0.4204 & -2.621 & 9.401 & 0.3410 & 1.467 & 3.538 \\
\hline PC16a & 0.4199 & 3.397 & 6.014 & 0.3432 & -1.966 & 4.484 \\
\hline PC23b & 0.3935 & 3.955 & 9.024 & 0.8636 & 22.127 & 12.416 \\
\hline PC15b & 0.3910 & -2.713 & 6.989 & 0.7464 & 6.324 & 5.401 \\
\hline PC213 & 0.3845 & 1.501 & 5.685 & 0.4049 & 2.319 & 5.288 \\
\hline PC39c & 0.3633 & 1.373 & 5.195 & 0.7080 & 7.650 & 6.705 \\
\hline EducOut9 & 0.3618 & 1.633 & 3.545 & 0.3150 & 0.304 & 13.409 \\
\hline PC15a & 0.3613 & -2.843 & 5.845 & 0.9248 & 16.629 & 7.451 \\
\hline PC43a & 0.3545 & -1.375 & 2.863 & 0.2363 & 0.334 & 2.362 \\
\hline PC113 & 0.3518 & 2.692 & 5.787 & 0.3321 & 0.880 & 5.298 \\
\hline PC19c & 0.3511 & -2.437 & 8.052 & 0.2226 & 0.289 & 1.840 \\
\hline ProfDevTeac1 & 0.3251 & 0.619 & 4.800 & 0.3150 & 2.142 & 5.498 \\
\hline PC26a & 0.3228 & -1.768 & 4.374 & 0.2537 & 0.118 & 4.206 \\
\hline PC21 & 0.3123 & 0.109 & 7.211 & 0.3849 & 1.808 & 3.607 \\
\hline PC211a & 0.3108 & 1.180 & 3.954 & 0.3390 & -1.078 & 3.249 \\
\hline PC12 & 0.3104 & -0.744 & 13.500 & 0.2977 & 0.653 & 3.107 \\
\hline ICT & 0.2931 & -0.105 & 3.936 & 0.3204 & -2.103 & 6.900 \\
\hline PC211b & 0.2816 & 0.654 & 2.192 & 0.3368 & 0.402 & 5.050 \\
\hline PC22 & 0.2802 & 0.570 & 2.878 & 0.3711 & 2.560 & 5.558 \\
\hline PC26c & 0.2789 & 0.794 & 2.922 & 0.7751 & -6.840 & 5.202 \\
\hline
\end{tabular}


Review of Economic Analysis 13 (2021) 157-212

\begin{tabular}{|c|c|c|c|c|c|c|}
\hline & \multicolumn{3}{|c|}{ Gini-BMA } & \multicolumn{3}{c|}{ OLS-BMA } \\
\hline & PIP & PSE & PSD & PIP & PSE & PSD \\
\hline PC111b & 0.2785 & -0.494 & 3.038 & 0.2430 & 0.268 & 1.958 \\
\hline PC33a & 0.2756 & -0.337 & 2.910 & 0.4361 & -1.935 & 3.152 \\
\hline PC16c & 0.2672 & -0.284 & 2.957 & 0.2697 & 0.445 & 2.956 \\
\hline PC14 & 0.2668 & 0.358 & 3.961 & 0.354 & -1.457 & 4.319 \\
\hline PC16b & 0.2547 & -0.403 & 4.321 & 0.2571 & -0.321 & 2.790 \\
\hline PC13b & 0.2285 & 0.315 & 2.246 & 0.3370 & 2.352 & 7.989 \\
\hline PC29c & 0.2275 & 0.149 & 1.894 & 0.3556 & 1.864 & 4.832 \\
\hline
\end{tabular}

Note: The values in yellow colour are above the $50 \%$ PIP and are determined as robust determinants

Table 6: Summary of the robust determinants under Gini and OLS analysis

\begin{tabular}{|c|c|c|c|}
\hline Variables & $\begin{array}{c}\text { Under Gini } \\
\text { Analysis }\end{array}$ & Variables & $\begin{array}{c}\text { Under OLS } \\
\text { Analysis }\end{array}$ \\
\hline $\begin{array}{l}\text { Students with an } \\
\text { immigrant background }\end{array}$ & PC110a (+) & & PC110a (-) \\
\hline $\begin{array}{l}\text { Students' evaluation } \\
\text { and assessment }\end{array}$ & PC34 (-) & & PC34 (+) \\
\hline Repetition of a grade & EducOut1 (+) & & EducOut1 (-) \\
\hline $\begin{array}{l}\text { Non-attendance in pre- } \\
\text { primary education }\end{array}$ & EducOut2 (-) & & EducOut2 (-) \\
\hline School characteristics & PC25a (+) & & PC15a $(+)$ \\
\hline $\begin{array}{l}\text { Average time spent in } \\
\text { learning }\end{array}$ & $\mathrm{PC} 25 \mathrm{~b}(+)$ & & PC15b (+) \\
\hline $\begin{array}{l}\text { Expectations to work in } \\
\text { science-related fields }\end{array}$ & PC23a (-) & & PC13a (-) \\
\hline $\begin{array}{l}\text { Relative risk/increased } \\
\text { likelihood }\end{array}$ & $\mathrm{PC} 33 \mathrm{~b}(+)$ & & $\mathrm{PC} 23 \mathrm{~b}(+)$ \\
\hline $\begin{array}{l}\text { Difference in science } \\
\text { performance between } \\
\text { immigrant and non- } \\
\text { immigrant students }\end{array}$ & PC110b (-) & $\begin{array}{l}\text { Difference in } \\
\text { science } \\
\text { performance }\end{array}$ & PC39c (+) \\
\hline $\begin{array}{l}\text { Attendance in pre- } \\
\text { primary education }\end{array}$ & PC11 (-) & $\begin{array}{l}\text { Skip/arrive late } \\
\text { in class }\end{array}$ & PC26c (-) \\
\hline $\begin{array}{l}\text { Average time spent in } \\
\text { studying after school }\end{array}$ & PC17(-) & & \\
\hline $\begin{array}{l}\text { Students' evaluation } \\
\text { and assessment }\end{array}$ & $\mathrm{PC} 44(+)$ & & \\
\hline $\begin{array}{l}\text { Resources for science } \\
\text { course }\end{array}$ & PC111a (+) & & \\
\hline
\end{tabular}

Notes: There are two variables that refer to pre-primary education and are indicated with yellow color 


\section{References:}

Aguilar R. and R. Tansini (2012). Joint analysis of preschool attendance and school performance in the short and long-run. International Journal of Educational Development. Vol. 32, pp. 224-231.

Akabayashi H. and R. Tanaka (2013). Long-term effects of pre-schooling on educational attainments. GRIPS Discussion paper, pp. 12-21.

Alexander K. L., D. R. Entwisle, and S. L. Dauber (1994). On the Success of Failure. New York: University of Cambridge Press.

Bainbridge J., M. Meyers, S. Tanaka and J. Waldfogel (2005). Who gets an early education? Family income and the gaps in enrolment of 3-5-year olds from 1968-2000. Social Science Quarterly. Vol. 86(3), pp.724- 745.

Baker M., J. Gruber and K. Milligan (2005). Universal Child Care, Maternal Labour Supply and Family Well-Being. NBER Working Paper No. 11832.

Barnett S. (1992). Benefits of compensatory preschool education. Journal of Human Resources. Vol. 27, pp. 279-312.

Barnett S. (1995). Long-term effects of early childhood programs on cognitive and school outcomes. The Future of Children. Vol.5 (3), pp. 25-50.

Barnett W. S. (2011). Effectiveness of early educational intervention. Science. Vol. 333 (6045), pp. $975-977$.

Barnett W. S., J.T. Hustedt, K.B. Robin and K.L. Schulman (2004). The state of preschool: 2004 state preschool yearbook. New Brunswick, NJ: NIEER

Bauchmüller R., M. Gørtz and A. W. Rasmussen (2014). Long-run benefits from universal high-quality pre-schooling. Early Childhood Research Quarterly. Vol. 29, pp. 457-470.

Becher G. (1964). Human Capital: A Theoretical and Empirical Analysis, with Special Reference to Education. University of Chicago Press, Chicago.

Becker G. (1981). A treatise on the Family. Cambridge, Mass.: Harvard University Press.

Becker G. (1985). Human Capital, Effort, and the Sexual Division of Labour. Journal of Labour Economics. Vol. 3 (1, pt.), pp. S33-S58.

Becker G. S. and N. Tomes (1986). Human Capital and the Rise and Fall of Families. Journal of Labour Economics. Vol. 4(3, pt.2), pp. S1-S39.

Begun J. and T.S. Eicher (2008). In search of an environmental Kuznets curve in sulphur dioxide concentrations: a Bayesian model averaging approach. Environment and Development Economics, Vol. 13, pp. 795-822.

Behrman J. R. and N. Birdsall (1983). The quality of schooling: Quantity alone is misleading. The American Economic Review. Vol. 73(5), pp. 928-946.

Berger J.O. and L.R. Pericchi (1996). The intrinsic Bayes Factor for model selection and prediction. Journal of the American Statistical Association. Vol. 91, pp. 109-122. 
Berger J.O. and L.R. Pericchi (2001). Objective Bayesian methods for model selection: Introduction and comparison. Model selection. IMS Lecture Notes- Monograph Series. Vol. 38, pp. 135-207.

Berlinski S., S. Galiani and M. Manacorda (2008). Giving children a better start: Preschool attendance and school-age profiles. Journal of Public Economics. Vol. 92, pp. 1416-1440.

Berlinski S., S. Galiani and P. Gertler (2009). The effect of pre-primary education on primary school performance. Journal of Public Economics. Vol. 93, pp. 219-234.

Bernardo J.M. and A.F.M. Smith (1994). Bayesian Theory. John Wiley, Chichester.

Bjorklund A. and K. Salvanes (2011). Education and Family Background: Mechanisms and Policies. in Hanushek, Eric, Machin, Stephen and Ludger Woessmann ed., Handbook of the Economics of Education, Vol. 3, Elsevier.

Blau D. and J. Currie (2006). Pre-school, day care, and after school care: who's minding the kids? In: Hanushek, Eric, Welch, Finis (Eds.), Handbook of the Economics of Education, Elsevier, Amsterdam, Vol.2, pp. 1163-1278.

Bottolo L. and S. Richardson (2008). Fully Bayesian variable selection using g-priors. Working paper. Imperial College.

Brock W.A. and S.N. Durlauf (2001). Growth empirics and reality. The World Bank Economic Review. Vol. 15, pp. 229-272.

Brock W.A, S.N. Durlauf and K.D. West (2003). Policy evaluation in uncertain economic environments. Brookings Papers on Economic Activity, Vol. 2003, pp. 235-301.

Brooks-Gunn J. (2003). Do you believe in magic? What we can expect from early childhood intervention programs? SRCD Social Policy Report, Vol. 17, pp. 3-14.

Brown P.J., M. Vannucci and T.Fearn (1998). Multivariate Bayesian variable selection and prediction. Journal of the Royal Statistical Society. Series B (Statistical Methodology). Vol. 60, pp. 627-641.

Brown P.J., M. Vannucci and T.Fearn (2002). Bayes model averaging with selection of regressors. Journal of the Royal Statistical Society. Series B (Statistical Methodology). Vol. 64, pp. 519-536.

Burhan N.A.S., Y. Kurniawan, A.H. Sidek and M.R. Mohamad (2014). Crimes and the Bell curve: The role of people with high, average, and low intelligence. Intelligence. Vol.47, pp.12-22.

Carcea M. and R. Serfling (2015). A Gini autocovariance function for time series modelling. Journal of Time Series Analysis. Vol. 36, pp. 817-838.

Carneiro P. and J. Heckman (2003). Human Capital Policy. NBER Working Paper No. w9495.

Carvalho C.M., N.G. Polson and J.G. Scott (2010). The horseshoe estimator for sparse signals. Biometrika. Vol. 97, pp. 465-480. 
Cascio E. U. (2009). Do investments in universal early education pay off? Long-term effects of introducing kindergartens into public schools. National Bureau of Economic Research, Working Paper 14951.

Ceriani L. and P. Verme (2012). The origins of the Gini index: extracts from Variabilità e Mutabilità (1912) by Corrado Gini. The Journal of Economic Inequality. Vol.10, pp. 421443.

Charpentier A., N. Ka, S. Mussard and O.H Ndiaye (2019). Gini regressions and Heteroskedasticity. Econometrics. Vol.7, pp.?

Chetty R., J.N. Friedman, N. Hilger, E. Saez, D. Whitmore Schanzenbach, and D. Yagan (2011). How does your kindergarten classroom affect your earnings? Evidence from Project STAR. Quarterly Journal of Economics, Vol. 126(4), pp. 1593-1660.

Chipman H., E.I. George and R.E. McCulloch (2001). The practical implementation of Bayesian Model Selection. In Model Selection (P.Lahiri, ed.). IMS Lecture NotesMonograph Series. Vol. 38., pp. 70-134.

Clyde M. and E.I. George (2004). Model uncertainty. Statistical Science. Vol. 19, pp. 81-94.

Cui W. and E.I. George (2008). Empirical Bayes vs Fully Bayes variable selection. Journal of Statistical Planning and Inference. Vol. 138, pp. 888-900.

Cumberworth S. and E. Cumberworth (2018). Does school composition matter more for lowerSES Students? A cross- national examination of school socioeconomic composition, individual socioeconomic status, and standardizes test scores.

Cunha F., J. Heckman, L. Lochner and D. Masterov (2006). Interpreting the Evidence on Life Cycle Skill Formation. in Hanushek, Eric and Finis Welch ed., Handbook of the Economics of Education, Vol. 1, Elsevier.

Currie J. (2001). Early childhood education programs. Journal of Economic Perspectives. Vol. 15, pp. 213-238.

Danziger S. and J. Waldfogel (2000). Investing in children: What do we know? What should we do? Centre for Analysis for Social Exclusion, LSE, CASE papers 34.

Dickson M. (2012). The effect of free pre-school education on children's subsequent academic performance: Empirical Evidence from England.

Doppelhofer G., R.I. Miller and X. Sala-i-Martin (2004). Determinants of long-term growth: A Bayesian Averaging of Classical Estimates (BACE) approach. American Economic Review. Vol. 94, pp. 813-835.

Drapper D. (1995). Assessment and propagation of model uncertainty. Journal of the Royal Statistical Society. Series B(Methodological). Vol.57, pp.45-97.

Dumas C. and A. Lefranc (2010). Early schooling and later outcomes: Evidence from preschool extension in France. From parents to children: the intergenerational transmission of advantage, Russel Sage Foundation, 978-0-87154-045-4. ffhal-02528291f 
Durlauf S.N., A. Kourtellos and C.M. Tan (2008). Are any growth theories robust?. The Economic Journal. Vol. 118, pp. 329-346.

Durlauf S.N., A. Kourtellos and C.M. Tan (2012). Is God in the details? A Re-approximation of the Role of religion in economic growth. Journal of Applied Econometrics. Vol.27, pp. 1059-1075.

Efroymson M.A. (1960). Multiple Regression Analysis. In Mathematical Methods for Digital Computers, pp. 191-203. Wiley: New York.

Eicher T. S., A. Lenkoski and A.E Raftery (2009). Bayesian model averaging and endogeneity under model uncertainty: an application to development determinants. Working paper No.94, University of Washington.

Eicher T.S., C. Papageorgiou and A.E. Raftery (2011). Default priors and predictive performance in Bayesian Model Averaging, with application to growth determinants. Journal of Applied Econometrics. Vol. 26, pp. 30-35.

Eicher T. S, C. Henn and C. Papageorgiou (2012). Trade Creation and Diversion Revisited: Accounting for model uncertainty and natural trading partner effects. Journal of Applied Econometrics. Vol. 27, pp. 296-321.

Eide E.R. and D. D. Goldhabe (2005). Grade retention: What are the costs and benefits? Journal of Education Finance, Vol. 31 (2), pp. 195-214.

Eklund J. and S. Karlsson (2007). Forecast combination and model averaging using predictive measures. Econometric Reviews. Vol. 26, pp. 329-363.

Entwisle D. and K.L. Alexander (1993). Entry into school: The beginning school transition and educational stratification in the United States. Annual Review of Sociology. Vol. 19, pp.401-423.

Erdogdu F. and E.Edrogdu (2015). The impact of access to ICT, student background and school/home environment on academic success of students in Turkey: an international comparative analysis. Computers \& Education. Vol.82, pp. 26-49.

Esping-Andersen G., I. Garfinkel, W.J. Han, K. Magnuson, S. Wagner and J. Waldfogel (2012). Childcare and school performance in Denmark and the United States. Children and Youth Services Review. Vol. 34(3), pp. 576-589.

Feldkircher M. and S. Zeugner (2009). Benchmark priors revisited: On adaptive shrinkage and the supermodel effect on Bayesian Model Averaging. IMF Working paper 09/202.

Fernandez C., E. Ley and M.F.J. Steel (2001a). Model uncertainty in cross-country growth regressions. Journal of Applied Econometrics. Vol. 16, pp. 563-576.

Fernandez C., E. Ley and M.F.J. Steel (2001b). Benchmark priors for Bayesian model averaging. Journal of Econometrics. Vol. 100, pp. 381-427.

Forte A., M.J. Bayarri, J.O. Berger and G. Garcia-Donato (2010). Closed form objective Bayes factors for variable selection in linear models poster presentation. In: Frontiers of Statistical Decision Making and Bayesian Analysis in Honour of Jim Berger. 
Carneiro P. and J. Heckman (2003). Human Capital Policy. NBER Working Paper No. w9495.

Garratt A., K. Lee, M.H. Pesaran and Y. Shin (2003). Forecast uncertainties in Macroeconomic modelling: An application to the U.K. economy. Journal of the American Statistical Association. Vol. 98, pp. 829-838.

Garthwaite P.H and e. Mubwandarikwa (2010). Selection of weights for weighted model averaging. Australian \& New Zealand Journal of Statistics. Vol. 52, pp. 363-382.

George E.I. and R.E. McCulloch (1993). Variable selection via Gibbs Sampling. Journal of the American Statistical Association. Vol. 88, pp. 881-889.

George E.I. (1999a). Bayesian model selection. Encyclopedia of Statistical Sciences Update. In: Kotz, S., C. Read and D.L. Banks (Eds.), Wiley, New York. Vol. 3, pp. 39-46.

George E.I. (1999b). Discussion of Bayesian model averaging and model search strategies. In: Clyde M.A., J. Bernardo, J. Berger, A. David, and A. Smith (Eds), Bayesian Statistics, Clarendon Press, Oxford. Vol.6, pp.157-177.

George E.I. and D.P. Foster (2000). Calibration and empirical Bayes variable selection. Biometrika. Vol. 87, pp. 731-747.

George E.I. (2010). Dilution priors: Compensating for model space redundancy. Borrowing Strength: Theory Powering Applications- A Festschrift for Lawrence D. Brown. IMS Collections. Vol. 6, pp. 158-165.

Giambona F. and M. Porcu (2018). School size and students' achievement. Empirical evidences from PISA survey data. Socio-Economic Planning Sciences. Vol.64, pp.66-77.

Gilliam W. S. and E. Zigler (2001). A critical meta-analysis of all evaluations of state-funded preschool from 1977 to 1998: Implications for policy, service delivery and program evaluation. Early Childhood Research Quarterly. Vol. 15, pp. 441-473.

Goodman A. and B. Sianesi (2005). Early education and children's outcomes: How long do the impacts last? Fiscal Studies. Vol. 26(4), pp. 513-548.

Gormley W.T. and T. Gayer (2005). Promoting School Readiness in Oklahoma: An Evaluation of Tulsa's Pre-K Program. Journal of Human Resources. Vol.40(3), pp. 533-558.

Gormley W.T, T. Gayer, D. Phillips and B. Dawson (2005). The effects of universal pre-K on cognitive development. Developmental Psychology. Vol. 41(6), pp. 872-884.

Goux D. and E. Maurin (2008). Preschool enrolment, mother's participation in the labour market and children's subsequent outcomes. mimeo

Grange C.W.J. and H.F. Uhlig (1990). Reasonable Extreme-Bounds Analysis. Journal of Econometrics. Vol. 44, pp. 159-170.

Greene J. P. and M. A. Winters (2004). An Evaluation of Florida's Program to End Social Promotion. Manhattan Institute for Policy Research Education Working Paper No. 7, December. 
Hanushek E. and L. Wößmann (2006). Does educational tracking affect performance and inequality? Differences-in-differences evidence across countries. Economic Journal, Vol. 116, pp. 63-76.

Heckman J. (2006). The Economics of Investing in Children (Policy Briefing no. 1). Dublin: UCD Grary Institute.

Heckman J. and L. Lochner (2000). Rethinking education and training policy. In: Danziger, S.; Waldfogel, J., editors. Securing the Future. Russell Sage Foundation; New York: 2000.

Heckman J. J., A.B. Krueger and B.M. Friedman (2002). Inequality in America: What role for human capital policies? (14th ed.). Cambridge, MA: MIT Press.

Heckman J., R. Pinto, and P. Savelyev (2013). Understanding the Mechanisms through Which an Influential Early Childhood Program Boosted Adult Outcomes. American Economic Review. Vol. 103 (6), pp. 2052-86.

Helal S., J. Li, L. Liu, E. Ebrahimie, S. Dawson, and D.J. Murray (2019). Identifying key factors of student academic performance by subgroup discovery. International Journal of Data Science and Analytics. Vol. 7, pp. 227-245.

Hettmansperger T.P. (1984). Statistical inference based on ranks. New York: John Wiley and Sons.

Hoeting A., D. Madigan, A.E. Raftery and C. T. Volinsky (1999). Bayesian Model Averaging: A Tutorial. Statistical Science. Vol. 14, pp. 382-401.

Jackman S. and B. Western (1994). Bayesian inference for comparative research. The American Political Science Review. Vol.88, pp. 421-423.

Jacobs B. A. and L. Lefgren (2004). Remedial education and student achievement: A regression-discontinuity analysis. The Review of Economics and Statistics. Vol. 86(1), pp. 226-244.

Jeffreys H. (1961). Theory of Probability, third edition. Clarendon Press, Oxford.

Jerrim J., M. Oliver and S. Sims (2019). The relationship between inquiry-based teaching and students' achievement. New evidence from a longitudinal PISA study in England. Learning and Instruction, Vol. 61, pp. 35-44.

Jolliffe I. T. (2002). Principal Component Analysis. 2nd Edition, Springer, New York.

Karweit N. L. (1999). Grade Retention: Prevalence, Timing, and Effects. CRESPAR Report No. 33. Available online at http://scov.csos.jhu.edu/crespar/reports/report33chapt1.html.

Kass R.E. and A.E. Raftery (1995). Bayes factors. Journal of the American Statistical Association. Vol. 90, pp. 773-795.

Kass R.E. and L. Wasserman (1995). A reference Bayesian test for nested hypotheses and its relationship to the Schwarz criterion. Journal of the American Statistical Association. Vol. 90, pp. 928-934.

Knight A. and D. Hughes (1995). Developing social competence in the pre-school years. Australian Journal of Early Childhood. Vol. 20 (2), pp. 13-19. 
Knudsen E. I., J.J. Heckman, J.L. Cameron and J.P. Shonkoff (2006). Economic, neurobiological and behavioural perspectives on building America's future workforce. Proceedings of the National Academy of Sciences. Vol. 103(27), pp. 10155-10162.

Koop G. and D. Korobolis (2012). Forecasting inflation using Dynamic Model Averaging. International Economic Review. Vol. 53, pp. 867-886.

Kourtellos A., T. Stengos and C.M Tan (2013). The effect of Public Debt in Growth in Multiple Regimes. Journal of Macroeconomics. Vol.38 (Part A), pp.35-43.

Kourtellos A., C. Marr and C.M. Tan (2015). Robust determinants of intergenerational mobility in the land of opportunity. European Economic Review. Vol. 81, pp. 132-147.

Kourtellos A. and C.G. Tsangarides (2017). Robust correlates of growth spells: Do inequality and redistribution matter?. The Rimini Centre for Economic Analysis. Working paper 1520.

Laud P.W. and J.G. Ibrahim (1996). Predictive specification of prior model probabilities in variable selection. Biometrika. Vol. 83, pp. 267-274.

Leamer E.E. (1978). Specification searches: Ad hoc inference with nonexperimental data. New York: John Wiley and Sons.

Leamer E.E. (1983). Let's take the con out of Econometrics. The American Economic Review. Vol.73, pp. 31-43.

Leamer E.E. (1985). Sensitivity analyses would help. The American Economic Review. Vol. 75, pp. 308-313.

Lerman R.I and S. Yitzhaki (1984). A note on the calculation and interpretation of the Gini index. Economics Letters. Vol. 15, pp. 363-368.

Levine R. and D. Renelt (1992). A sensitivity analysis of cross-country growth regressions. The American Economic Review. Vol. 82, pp. 942-963.

Levin A.T. and J.C. Williams (2003). Robust monetary policy with competing reference models. Journal of Monetary Economics. Vol. 50, pp. 945-975.

Ley E. and M.F.J. Steel (2007). Jointness in Bayesian variable selection with applications to growth regression. Journal of Macroeconomics. Vol. 29, pp. 476-493.

Ley E. and M.F.J. Steel (2009). On the effect of prior assumptions in Bayesian model averaging with applications to growth regression. Journal of Applied Econometrics. Vol. 24, pp. 651674.

Ley E. and M.F.J. Steel (2012). Mixtures of g-priors for Bayesian model averaging with economic applications. Journal of Econometrics. Vol. 171, pp. 251-266.

Liang F., R. Paulo, G. Molina, M.A. Clyde and J.O. Berger (2008). Mixtures of g priors for Bayesian variable selection. Journal of the American Statistical Association. Vol. 103, pp. 410-423.

Lorence J., A.G. Dworkin, L.A. Toenjes and A.N. Hill (2002). Grade retention and social promotion in Texas, 1994-1999: Academic achievement among elementary school 
students. In D. Ravitch (Ed.), Brookings papers on education policy 2002 (pp. 13-52). Washington, DC: Brookings Institution.

Lorence J. and A.G. Dworkin (2006). Elementary Grade Retention in Texas and Reading Achievement Among Racial Groups: 1994-2002. Review of Policy Research. Vol.23 (5), pp. 999-1033.

Ludwig J. and D.L. Miller (2007). Does head start improve children's life chances? Evidence from a regression discontinuity design. Quarterly Journal of Economics. Vol. 122, pp. 159208.

Madigan D. and A.E. Raftery (1994). Model selection and accounting for model uncertainty in graphical models using Occam's window. Journal of the American Statistical Association. Vol. 89, pp. 1535-1546.

Madigan D. and J. York (1995). Bayesian graphical models for discrete data. International Statistical Review. Vol. 63, pp. 215-232.

Magnuson K. and J. Waldfogel (2005). Childcare, early education, and racial/ethnic test score gaps at the beginning of school. The Future of Children. Vol. 15(1), pp.169-196.

Magnuson K. A., C. Ruhm and J. Waldfogel (2007). Does prekindergarten improve school preparation and performance? Economics of Education Review. Vol. 26(1), pp. 33 - 51.

Maruyama Y. and E.I. George (2011). Fully Bayes factors with a generalized g-prior. The Annals of Statistics. Vol. 39, pp. 2740-2765.

Massanjala W.H. and C. Papageorgiou (2008). Rough and lonely road to prosperity: A reexamination of the sources of growth in Africa using Bayesian Model Averaging. Journal of Applied Econometrics. Vol. 23, pp. 671-682.

Meyers M., D. Rosenbaum, C. Ruhm and J. Waldfogel (2004). Inequality in early childhood education and care: What do we know? In: Neckerman, K., editor. Social Inequality. Russell Sage Foundation, New York: 2004.

Min C. and A. Zellner (1993). Bayesian and non-Bayesian methods for combining models and forecasts with applications to forecasting international growth rates. Journal of Econometrics. Vol. 56, pp. 89-118.

Mitchell T.J. and J.J. Beauchamp (1988). Bayesian variable selection in linear regression. Journal of the American Statistical Association. Vol. 83, pp. 1023-1032.

Moser M. and P. Hofmarcher (2014). Model priors revisited: Interaction terms in BMA growth applications. Journal of Applied Econometrics. Vol. 29, pp. 344-347.

Mussard S. and O.H. Ndiaye (2018). Vector autoregressive models: A Gini approach. Physica A: Statistical Mechanics and its Applications. Vol. 492, pp. 1967-1979.

Myers R. (1992). The Twelve who Survive: Strengthening Programmes of Early Childhood Development in the Third World. Routledge, London.

Myers R. (1995). Preschool Education in Latin America: Estate of Practice. PREAL Working Papers No. 1. 
Neuman M., S.B. Kamerman, J. Waldfogel and J. Brooks-Gunn (2003). Social policies, family types, and child outcomes in selected OECD countries. OECD Social, Employment, and Migration Working Paper No. 6.

Nikolaev B. and R. Salahodjaev (2016). The role of intelligence in the distribution of national happiness. Intelligence. Vol. 56, pp. 38-45.

OECD (2009). PISA Data Analysis Manual: SPSS Second Edition. OECD Publishing

O'Hagan A. (1995). Fractional Bayes Factors for model comparison. Journal of the Royal Statistical Society. Series B(Methodological). Vol. 57, pp. 99-138.

Olkin I. and S. Yitzhaki (1992). Gini Regression Analysis. International Statistical Review. Vol. 60, pp.185-196.

Pagan A. and A. Ullan (1999). Non-parametric techniques. Cambridge University press.

Pholphirul P. (2017). Pre-primary education and long-term education performance: Evidence from Programme for International Student Assessment (PISA) Thailand. Journal of Early Childhood Research. Vol. 15 (4), pp. 410-432.

Raftery A.E. (1988). Approximate Bayes factors for Generalized Linear Models. Technical Report 121, University of Washington, Department of Statistics.

Raftery A.E. (1993). Bayesian model selection in structural equation models. In K. A. Bollen \& J. S. Long (Eds.), Testing structural equation models (pp.163-180). Newbury Park, CA: Sage.

Raftery A.E. (1995). Bayesian model selection in social research. Sociological Methodology. Vol. 25, pp. 111-163.

Raftery A.E, D. Madigan and J.A. Hoeting (1997). Bayesian model averaging for linear regression models. Journal of the American Statistical Association. Vol. 92, pp. 179-191.

Reynolds A. J. (1993). Effects of a preschool plus follow-on intervention program for children at risk. Developmental Psychology. Vol. 30, pp. 787-804.

Reynolds A. J. (2000). Child, youth, and family services. Success in early intervention: The Chicago child-parent centers. University of Nebraska Press.

Reynolds A. J. (2000). Success in early intervention: The Chicago child-parent centers. Lincoln. NE: University of Nebraska Press.

Reynolds A.J, J.A. Temple, S.R. Ou, I.A. Arteaga and B.A.B White (2011). School-based early childhood education and age-28 well-being: Effects by timing, dosage, and subgroups. Science, Vol. 333(6040), pp. 360-364.

Roberts H.V. (1965). Probabilistic prediction. Journal of the American Statistical Association. Vol. 60, pp.50-62.

Sala-i-Martin X.X. (1997). I just ran two million regressions. The American Economic Review. Vol. 87, pp.178-183.

Schulman K., H. Blank and D. Ewen (1999). Seeds of Success: State Prekindergarten Initiatives 1998- 1999. Washington, DC: Children's Defense Fund. 
Serfling R. (2010). Fitting autoregressive models via Yule-Walker equations allowing heavy tail innovations. Working paper.

Shelef A. and E. Schechtman (2011). A Gini-based methodology for identifying and analysing time series with non-normal innovations. SSRN Electronic Journal. Vol.?, pp. 1-26.

Sirimaneetham V. and J. Temple (2006). Macroeconomic policy and the distribution of growth rates. CEPR Discussion paper 5642.

Sholderer O. (2017). Making education work: School autonomy and performance. East European Quarterly. Vol.45, pp. 27-56.

Steel M.F.J. (2020). Model Averaging and its use in Economics. Journal of Economic Literature. Vol. 58, pp. 644-719.

Strawderman W.E. (1971). Proper Bayes minimax estimators of the multivariate normal mean. The Annals of Mathematical Statistics. Vol. 42, pp. 385-388.

Stuart A. and J.K Ord (1987). Kendall's advanced theory of statistics, Vol.1, 5th ed., New York: Oxford University Press.

Taiwo A.A and J.B. Tyolo (2002). The effect of pre-school education on academic performance in primary school: a case study of grade one pupils in Botswana. International Journal of Educational Development. Vol. 22, pp. 169-180.

Tang Y. (2019). Immigration Status and Adolescent Life Satisfaction: An International Comparative Analysis Based on PISA 2015. Journal of Happiness Studies. Vol.20, pp. 1499-1518.

Tinajero C., S.M. Lemos, M. Araújo, M.J. Ferraces and M.F. Páramo (2012). Cognitive style and learning strategies as factors which affect academic achievement of Brazilian university students. Psicologia: Reflexão e Crítica, Vol.25, pp. 105-113.

Tobias J.L. and M. Li (2004). Returns to schooling and Bayesian Model Averaging: A union of two literatures. Journal of Economic Surveys. Vol. 18, pp. 153-180.

UNESCO (2005). EFA Global Monitoring Report. (Data available at: http://portal.unesco.org).

Velez E., E. Schiefelbein, J. Valenzuela (1993). Factors Affecting Achievement in Primary Education. World Bank, Washington, Working Paper No. 12186.

Volinsky C.T., D. Madigan, A.E. Raftery and R. A. Kronmal (1997). Bayesian Model Averaging in proportional hazard models: Assessing the risk of a stroke. Applied Statistics. Vol. 46, pp. 433-448.

Waldfogel J. (2002). Childcare, women's employment and child outcomes. Journal of Population Economics. Vol. 15, pp. 527-548.

Waldfogel J. (2006). What Children Need. Harvard University Press, Cambridge, Mass.

Waldfogel J. and E. Washbrook (2011). Income-related gaps in school readiness in the US and UK. In: Smeeding, T., et al., editors. Intergenerational Mobility Within and Across Nations. Russell Sage Foundation; New York: In press b 
Wößmann L. (2005). Families, School, and Primary-School Learning: Evidence for Argentina and Colombia in an International Perspective. The World Bank, Policy Research Working Paper 3537.

Yang K.E and S.H. Ham (2017). Truancy as systemic discrimination: Anti-discrimination legislation and its effect on school attendance among immigrant children. The Social Science Journal. Vol. 54, pp.216-226.

Yitzhaki S. and E. Schechtman (2004). The Gini instrumental variable, or the "double instrumental variable" estimator. Metron- International Journal of Statistics. Vol. LXII, pp. 287-313.

Yitzhaki S. and E. Schechtman (2013). The Gini Methodology: a primer on a Statistical Methodology. New York: Springer.

Zellner A. (1971). An introduction to Bayesian Inference in Econometrics. Wiley, New York.

Zellner A. and A. Siow (1980). Posterior odds ratios for selected regression hypotheses (with discussion). In: Bernardo J.M., M.H. DeGroot, D.V. Lindley and A.F.M. Smith (Eds.), Bayesian Statistics. University Press, Valencia, pp. 585-603.

Zellner A. (1986). On assessing prior distributions and Bayesian regression analysis with gprior distributions. In: Goel P.K. and A. Zellner (Eds.), Bayesian Inference and Decision Techniques: Essays in Honour of Bruno de Finetti. North-Holland, Amsterdam, pp. 233243.

Zheng A., E.M Tucker-Drob and D.A Briley (2019). National GDP, Science Interest, and Science Achievement: A Direct Replication and Extension of Tucker-Drob, Cheung and Briley (2014). Psychological Science, Vol. 30, pp. 776-788.

Zigler E. and W. Berman (1983). Discerning the future of early childhood intervention. American Psychologist. Vol. 38, pp. 894-906. 